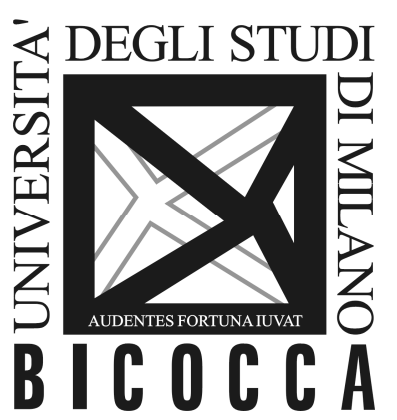

\author{
DEPARTMENT OF ECONOMICS, \\ MANAGEMENT AND STATISTICS \\ UNIVERSITY OF MILAN - BICOCCA
}

DEMS WORKING PAPER SERIES

\title{
The RES-induced Switching Effect Across Fossil Fuels: An Analysis of the Italian Day- Ahead and Balancing Prices and Their Connected Costs
}

Angelica Gianfreda, Lucia Parisio, Matteo Pelagatti

No. 360 - January 2017

Dipartimento di Economia, Metodi Quantitativi e Strategie di Impresa Università degli Studi di Milano - Bicocca 


\title{
The RES-induced Switching Effect Across Fossil Fuels: An Analysis of the Italian Day-Ahead and Balancing Prices and Their Connected Costs
}

\author{
Angelica Gianfreda ${ }^{\mathrm{a}, *}$, Lucia Parisio $^{\mathrm{a}}$, Matteo Pelagatti ${ }^{\mathrm{a}}$ \\ ${ }^{a}$ DEMS, University of Milano-Bicocca, Milan, Italy
}

\begin{abstract}
The massive introduction of RES in electricity markets has influenced the long-run dynamics of electricity prices and their interactions with conventional thermal production sources. Taking into account the Northern Italian zone characterized by a high solar PV and hydro penetration, we firstly provide empirical evidence on the fuels-electricity nexus across two samples characterized by low (2006-08) and high (2013-15) RES levels, both in the dayahead and balancing markets. Then, we estimate the costs for balancing power disentangling for technologies and comparing their dynamics across specific hours in both samples. We show that the fuels-electricity nexus has changed significantly in the day-ahead sessions and selectively in the balancing sessions. We also find evidence of high balancing prices that we interpret as a signal of strategic use of real time sessions by conventional producers. Our findings suggest policy makers to carefully monitor all trading sessions, especially those close to real time, to avoid the exercise of market power by few operators allowed to guarantee system security and to promptly adopt a capacity market.
\end{abstract}

Keywords: Electricity, Natural Gas, Coal, Oil, Cointegration, Balancing Costs

\section{Introduction}

In this paper we show how policy support towards renewable energy sources (RES) generation has affected the fuels-electricity nexus in the Italian market. This evidence is analyzed taking into account the relationship between fuel prices and day-ahead prices and, for the first time to our knowledge, between fuel prices and balancing prices. The intermittent and unpredictable nature of wind and solar production has made the real-time balancing activity of electricity systems more complex and relevant for the continuous matching of supply and demand. In this connection, we quantify the incurred costs for balancing needs across hours, technologies and market purpose, comparing them across two sample periods.

Transmission system operators (TSOs) are the formal responsible of system security, grid stability and instantaneous balance between inflows and outflows. They perform their tasks

*Corresponding author

Email addresses: angelica.gianfreda@unimib.it (Angelica Gianfreda), lucia.parisio@unimib.it (Lucia Parisio), matteo.pelagatti@unimib.it (Matteo Pelagatti) 
by negotiating regulation services in balancing market sessions with producers and/or consumers, remunerating increments or decrements in production and consumption. Balancing power differs on the basis of activation time, purpose and activation rules. Furthermore, its market design and power characteristics vary across countries even if a convergence process is taking place for a unique EU balancing area (see ACER, Recommendation No 03/2015).

Balancing sessions are dominated by conventional technologies (thermal, hydro and water pumping), which have the required degree of flexibility. Hence, units supplying regulation services usually enjoy a higher degree of market power in balancing than in day-ahead sessions, where they compete with RES producers. It must be recognized that in the last years the lower margins gained on the day-ahead market have changed the opportunity cost for thermal plants to participate to less competitive balancing sessions.

In this new scenario, we expect that electricity prices should be governed by new drivers with respect to the last decade. Indeed, we expect two distinct evolutionary dynamics of the fuels-electricity nexus induced by the significant growth of RES sources. On one side, we expect a less pronounced relationship among day-ahead electricity prices and fuel prices (oil, gas and coal), whereas, on the other side, we expect a stronger nexus between balancing and fuel prices, given that the control or regulation power is mainly granted by gas-fired plants. In these recent years while RES were gaining ground, we assisted to an increased profitability of coal-fired power plants because of decreasing coal prices in international markets.

We analyze the most relevant portion of the Italian market as a reference case: the Northern zone of Italy historically characterized by high hydro shares and, in the last few years, by high solar PV penetration. Hence, the influence of RES on long-run relations between electricity and fossil fuels may have produced important effects. Another interesting case would be the Southern zone, characterized by high wind penetration. However, we observed a low number of trades in balancing market sessions, which do not allow us to undertake the empirical analysis properly.

We focus on a time span from 2006 to the end of 2015 during which we observed a progressive increment of RES generation from low, or even absent, to high penetration. To this aim, we have divided the time series into two samples: the first one (2006-2008) representing the scenario for low RES penetration, whereas the second one (2013-2015) represents the scenario with high RES penetration. Between the two considered sample periods, also relevant regulatory changes have been introduced. For both samples, we analyze the long-run relationship between fuel prices (crude oil, natural gas and coal) aiming firstly at testing whether gas and coal prices are still strongly related to oil prices as it was documented in the past decade. Secondly, we study the relationship between fuels and electricity prices for both day-ahead and balancing market sessions. Indeed, prices in the latter sessions may be strongly affected by the increasing need of continuous balancing of demand and supply induced by new and intermittent RES-E generation. Obviously, electricity prices depend on fuels used to generate it. However, RES may have lessened this nexus for day-ahead prices, but the influence of fuels on balancing prices might be increased or decreased depending on how balancing needs have been fostered by RES penetration. Finally, we quantify costs associated to balancing services and compare them across the two considered samples to draw indications and suggestions for policy makers in charge of the market monitoring.

The paper is structured as follows: Section 2 reviews the main results obtained in the related literature, Section 3 provides a description of the structure of the Italian power 
market and its sessions, whereas the description of the data, the methodology employed and our empirical results are presented in Section 4 . Finally, Section 5 concludes.

\section{Literature Review}

Two streams of literature are of interest for our analysis. On the one side, we consider empirical papers analyzing the short and long run relationship among fuel prices. On the other side, we take into account papers dealing with the analysis of prices determined on the day-ahead markets and more recent studies devoted to prices formed in balancing market sessions. Oil and gas prices are usually found to exhibit a strong relationship, given that they are close substitutes in the long run. As a consequence, these fuel prices should form a long-term equilibrium level around which they "swing" in the short run. Using vector error correction estimates, Erdös (2012) shows that US natural gas prices have decoupled from European gas and crude oil prices since 2009. In the preceding period 1997-2008, US gas and oil prices co-moved in the short-term and were cointegrated in the long-term. Bosco et al. (2010) found strong evidence of a common long-term dynamics between electricity prices and gas prices for the major EU power exchanges. This long run common dynamics is one of the key factors explaining the almost strong integration among price series of the different power exchanges.

Several authors have shown the relationship between RES-E and electricity prices all around the world, as in Texas, Australia, Spain, Denmark, Norway, United Kingdom, The Netherlands and Germany; see for instance Woo et al. (2011), Ketterer (2014), Mulder and Scholtens (2013), Mauritzen (2013), Gelabert et al. (2011), and Cruz et al. (2011) among many others. However, these recent contributions are mainly devoted to the analysis of dayahead prices and do not consider the effect induced by RES on the long run relations between balancing and fuel prices.

Balancing markets are attracting an increasing interest in the last years both in the literature and in the regulatory practice. A number of recent papers consider different institutional designs and their ability to respond to high and increasing RES penetration. On the policy side, the Agency for the Cooperation of Energy Regulators (ACER) is considering an harmonization of rules and products to facilitate the coupling of balancing markets (after the success of the coupling initiative among day-ahead markets). ACER, in its Recommendation No $03 / 2015$ of 20 July 2015, suggests a number of changes on the network code with the objective to ensure the efficient integration and functioning of electricity balancing markets. Integrated balancing markets at the EU level imply cooperation between two or more TSOs with respect to i) the exchange of balancing services, ii) sharing reserves, or iii) operating the imbalance netting process. Newbery et al. (2016) estimate that the potential benefit of coupling interconnectors to increase the efficiency of trading in balancing services across borders amounts at 3.9 €billion per year at the EU level. About one third of this amount comes from shared balancing, which, therefore, appears to be highly valuable.

Hirth and Ziegenhagen (2015) provide a clear description of the main issues regarding balancing activities and relate them to the requirements imposed by the increasing share of variable RES production. They describe the German market data and, surprisingly, notice that while German wind capacity has tripled since 2008, balancing reserves have been reduced by $15 \%$ and balancing costs by $50 \%$. This finding is quite interesting because it seems to 
suggest that an increase in variable RES production can be obtained without incurring in extra costs for the system.

Some papers considers the functioning of balancing markets and different regulations across EU countries with particular attention devoted to the change of market design and rules due to the high RES penetration. Countries like Germany, France, Belgium and the Netherlands introduced more system flexibility by allowing negative prices, as described in Brijs et al. (2015). Negative prices emerging in day-ahead, intra-day and balancing markets are considered as signals of scarce downward flexibility, occurring when low load is combined with high non-programmable RES supply. They seem to be positively correlated with the forecast of wind and solar PV generation and negatively related with the forecast load. These observations suggest that systems endowed with a high share of RES should invest in technologies that enhance flexibility like electricity storage, demand response, interconnection capacity, and flexible generation. Moreover, attention should be paid to the pricing of balancing reserves, the market design and to the mechanisms to promote RES or to the calculation methods of imbalance prices that are not cost reflective.

Another stream of literature considers the conditions for participation of RES units in the balancing market, see for instance Fernandes et al. (2016). They analyze the current Spanish market design and suggest provisions for the adaptation of balancing arrangements to the participation of renewable producers. In Spain, where more than $20 \%$ of the total electricity is supplied by wind generators, the government recently launched a new remuneration scheme that provides renewable generators strong incentives to an active participation in electricity markets, including balancing sessions. Müsgens et al. (2014) analyze the institutional market design in German balancing power markets, where bidders submit simultaneously a capacity price bid and an energy price bid. Bids are selected starting from the lowest capacity price bid under the pay-as-bid pricing rule and, activation of balancing power, if needed, is requested from procured capacities, starting from the lowest accepted energy price (where again "payas-bid" is used). They show that, with a sufficiently competitive environment, a settlement rule based on uniform pricing ensures efficient energy call in the balancing power market. A scoring rule based on capacity prices only ensures an efficient production schedule. Thus, both rules together with rational bidding ensure simultaneous efficiency on the balancing power market and the wholesale electricity market.

Henriot (2014) investigates bidding strategies to manage wind power forecast errors in a continuous-trade intra-day market, approximated by a model with several subsequent trading windows. He compares different alternatives for wind power management by a central entity that can use intra-day market and/or balancing sessions, to adjust positions based on forecast updates. He finds that participation in the intra-day market strongly depends on the forecast uncertainty (reduced over time) and on the extra cost implied by late trading. Intra-day market sessions are considered a good market instrument for variable RES producers to adjust their positions near the real time. Analyses of Italian and Spanish case (two EU cases of organized adjustment market sessions) in Gianfreda et al. (2016a) and Chaves-Avila and Fernandes (2015) show that both the Italian and Spanish intra-day market have effectively contributed to balance renewable generation even if market design leaves room to possible strategic behavior across day-ahead and intra-day markets, giving rise to higher system costs. In particular, Gianfreda et al. (2016a) study the dynamic of day-ahead and balancing prices looking at long-run inter-relationship motivated by the time of market sessions and trying to 
explain the price spread in terms of electricity generated by hydro, wind, solar and geothermal sources. At the same time, Gianfreda et al. (2016b) look at the relationship between dayahead electricity prices, gas and coal prices in several EU countries, showing that the modified nexus has affected the creation of an internal energy market for Europe. However, in the international comparison, they only consider the single national price determined on the Italian day-ahead market and, given that this "PUN" price is a weighted average of zonal prices, it consequently smooths the impact of RES production across zones. Furthermore, the dependence of electricity prices from oil is not considered (taking for granted the relationship between oil and gas), as well as zonal balancing prices are not investigated.

\section{Background on Italian Power Market and its Balancing}

Wholesale electricity markets are platforms where bids for demand and supply of physical energy are submitted and production and consumption programs are defined under a cost minimizing objective. They are organized in a sequence of several sessions starting on the day-ahead and closing near the delivery time. The final session is the balancing market, where TSOs refine any deviations from production and consumption plans that occur after the gate closure of intra-day market. Balancing activities have been traditionally considered by TSOs as "security mechanisms" to maintain grid stability. In recent years this view has been partially abandoned in favor of a new balancing market design that enhances cost efficiency. Moreover, the recent increase in variable and intermittent RES generation across EU countries has challenged the design of balancing markets.

The Italian power generation mix has substantially changed in the last five years. Its evolution is depicted in Figure 1, where the shares of technology generation and RES penetration levels are shown together with the yearly dynamics of demand (in TW on the right axis). We can notice that RES sources, except hydro, were absent in 2006 whereas, in 2012,
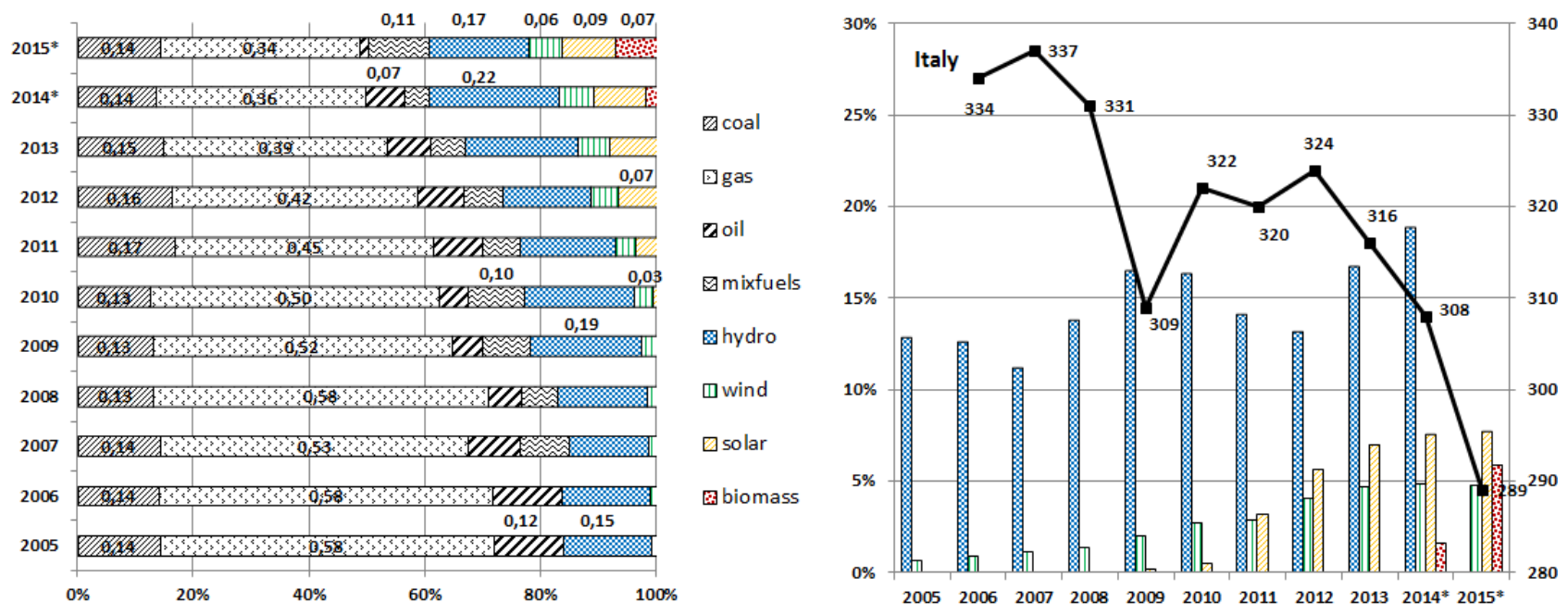

Figure 1: Italian shares by technology generation (on the left), and RES penetration together with Demand levels in TW (on the right). * means that data for 2014 and 2015 are provisional. Data Source: ENTSO-E.

solar production covered more than $7 \%$ of Italian demand for electricity. More generally, 
wind, solar and biomass shares in power generation increased substantially in a time span of few years, whereas hydro production remained stable but variable according to water availability. At the same time, the share of conventional thermal power plants dropped from $80 \%$ at the beginning of 2012 to $48 \%$ in 2015. Among fossils, gas primarily drives the generation, followed by coal, oil and mixed fuels, whereas no nuclear generation is available. The analysis of the Italian generation mix suggests us to conduct our study considering two separate samples: 2006-08 and 2013-15. Moreover, an institutional change occurred between the first and the second sample: the 'adjustment market' was replaced by a number of intra-day market sessions in 2009.

The Italian Power Exchange (IPEX) is organized in the day-ahead, intra-day and ancillary service markets. The day-ahead market (mercato del giorno prima, MGP) is the wholesale marketplace where demand/supply bids are submitted for the delivery of physical energy for each hour of the following day. It works under the marginal pricing rule and the equilibrium price is unique on all the territory and islands in the absence of line congestions ${ }^{1}$. It is quite liquid with a share of $70.9 \%$ of total electricity exchanged in the country and the number of operators largely increased from 73 in 2004 (year of liberalization) to 259 in 2015. RES-E production is sold on the MGP by the Gestore dei Servizi Energetici ${ }^{2}$ (GSE), and it enjoys priority dispatch. Therefore, the relevant portion of demand open to competition of all other conventional units is residual with respect to quantities allocated first to RES. The combination of low demand and evolving productive mix produced two main effects on the MGP: on the one side, we registered a decrease in average hourly prices; on the other side, we registered a change in the marginal technology, with an increase in the proportion of hours in which coal plants were price setter in the market (from $7 \%$ in 2013 to $11 \%$ in 2014) at the expense of CCGT plants.

Starting from 2010, we assisted to a change in the generation mix: conventional sources (gas, coal and oil) decreased their impact by 20\% from 2010 to 2015, while RES sources steadily increased their role, accounting for $42.9 \%$ of total purchases at the end of 2014 . Moreover, MGP registered a decrease in demand levels in almost all hours (-2.5\% in 2013-14) and a lower yearly peak (at $51.5 \mathrm{GW}$ with $-4.4 \%$ in 2013-14): in historical terms, the Italian demand in 2015 showed levels comparable with those registered in year 2002.

The increasing RES-E has added uncertainty to planned volumes on MGP, given that its session opens nine days before the day of delivery and closes at 12:00 p.m. of the day before delivery. As a consequence, the quantities bid by solar and wind units are based on forecasts while the effective load is known only in real time. This determines a higher level of volatility in production, which has to be hedged with the reserves for real time balancing. However, five intra-day market sessions (MIs) take place between MGP and balancing sessions. They represent a good instrument used by non programmable RES sources to adjust their production program (for a detailed description and analysis see Gianfreda et al. (2016a)).

The ancillary service market (mercato dei servizi di dispacciamento, MSD) opens at 12:55

\footnotetext{
${ }^{1}$ When congestions occur, zonal configurations emerge as consequence of market splitting and the price paid to producers differs across zones.

${ }^{2} \mathrm{GSE}$ is a public company acting on behalf of the Italian Ministry of Economic Development. It manages all the activities related to RES, from the units' qualification as "green producers" to the selling of electricity produced by RES units in the MGP.
} 
p.m. of the day before delivery. It consists of a scheduling sub-stage ("ex-ante MSD" with 4 sessions) and a balancing market (MB) with 5 sessions. MSD is the marketplace where the Italian TSO, Terna, negotiates all resources necessary to guarantee the system security, including dispatching services useful for resolving intra-zonal congestions, the establishment of an adequate reserve and real time balancing. The ex-ante MSD and MB are based on the "pay-as-bid" pricing mechanism (a reference price usually calculated as the weighted average of all accepted bids, both for purchases and for sales). In the ex-ante MSD, Terna accepts energy demand bids and supply offers in order to relieve congestions and to create reserve margins. During MB sessions, Terna accepts energy demand bids and supply offers in order to provide its service of secondary control and to balance energy injections into and withdrawals from the grid in real time. Bids submitted in MB sessions can only contain better economic conditions with respect to MSD bids, otherwise ex-ante MSD bids remain valid. Italian suppliers of balancing power are obliged to deliver energy under fixed technical conditions, like time of response, ramp rates and duration.

In general, balancing products can be divided into two main categories: i) balancing capacity, which refers to the generation (or consumption) capacity reserved in advance (i.e. capacity not committed in other markets) and kept available to the TSO for balancing purposes and ii) balancing energy, which refers to the actual variation of generation (or consumption) with the purpose of reestablishing the balance between generation and demand in real time. Furthermore, it is possible to distinguish between 'upward' reserve (for balancing capacity/energy procured to compensate a negative imbalance) and 'downward' reserve (for balancing capacity/energy procured to compensate a positive imbalance). In principle, market participants are obliged to comply with the production/consumption program established in the day-ahead and in the intra-day markets and they are financially responsible for any deviations with respect to their market schedules.

The increment of RES-E in MGP and the related displacement of conventional technologies have produced relevant consequences not only in the MGP itself (see Bigerna et al., 2016 Sapio, 2015), but even in the downstream market segments, where energy is exchanged close to the time of delivery and only qualified (thermal, hydro and water pumping) units are allowed to bid.

The Italian authority (Autorità per l'Energia Elettrica, il Gas e il Sistema Idrico, AEEGSI) documented that the dismissal of old thermal units (not replaced by new and more efficient ones) reduced the total power entitled to act in MSD from 73.5 to $70 \mathrm{GW}$ in the last three years, with the thermal segment of MSD registering the main reduction (from 60 to 56.6 GW). This reduction of available power in MSD produced a consequent reduction in the adequacy level ${ }^{3}$ because, to guarantee system security, the TSO cannot rely on units already in operation, like conventional gas plants, but it has also to activate CCGT units, which were out of the merit order in the MGP (AEEGSI (2015)). This had economical consequences in terms of the recovery of starting costs, which are low but not negligible especially if they have to be spread on a low number of operating hours. For this reason, AEEGSI introduced from 2014 a start-up fee to be paid to cold units offering a readiness status for balancing

\footnotetext{
${ }^{3}$ AEEGSI classifies four levels of system adequacy on the basis of types of plants that have to be called into operation for balancing needs of the system; this level decreased in some hours from level 1 to level 2.
} 
needs.

The authority also shows that the balance of Terna's operations is negative and this represents a cost for the system covered by the so-called uplift component. Its value was $3.82 € /$ MWh in 2009, but it almost doubled in 2014 (being equal to $6.25 € / \mathrm{MWh}$ ). The main cost components are represented by: 1) 'the planning of services' (approvvigionamento servizi) concerning activities in the ex-ante MSD sessions, which was mainly stable around one billion€ across years; 2) the 'energy component' (componente energia) taking into account all realized imbalances, which turned from being a profit to represent an increasing substantial cost from 127 Mln€ in 2011 to 459 Mln€ in 2014; 3) 'contracts' to secure (mainly upward) reserves for $3 \mathrm{GW}$ in 2014, with stable costs in the last years and finally, 4) 'the start-up and status change' (gettone di avviamento e cambio assetto) determining a cost of 90 Mln€ in 2013 and 82 Mln€ in 2014. Therefore, over a total cost of 1,756 Mln€ in 2014, the 'start-up and status change' represents only $4.7 \%$ of total costs, whereas the 'energy component' represents a larger share of $26 \%$, according to the latest available report, AEEGSI (2015). For this reason, in the quantification of balancing costs, we concentrate mainly on the 'energy component' in addition to the necessary 'planning of services'.

\section{Data, Methods and Results}

\subsection{Data Description and Preliminary Analysis}

Our analysis aims firstly at assessing the interdependence of fuel prices and their effects on electricity prices, taking into account both day-ahead and balancing sessions. Secondly, we measure the impact of RES on balancing costs, considering the dynamics of balancing prices and quantities.

Therefore, in the first part we consider electricity day-ahead and balancing prices together with fuel prices. We also take into account an important driver of electricity prices, namely the electricity demand, proxied by the system load ${ }^{4}$. To account for the different configurations of daily demand levels, we consider electricity prices determined at specific hours. An appropriate choice of hours is relevant to isolate effects on electricity prices induced by demand from the effects due to RES production. RES-E generation has been collected from the Italian system operator Gestore dei Mercati Energetici, GME. The inspection of the intra-daily profiles in Figure 2 shows the lowest loads at hours 3-5, midday peaks around hours 11-12, and evening peaks at hours 18-20. Then, to detect the effect of solar PV, wind and hydro, we have selected hours 11, 13, 19, whereas hour 3 allows us to control for low values of load and RES-E generation. Furthermore, we consider hours 9 and 21 to include the ramp-up and -down hours, during which demand noticeably increases/decreases. At these hours, we can detect the solar effect, since irradiation is increasing at hour 9 and decreasing at hour 19. In addition, RES generation is quickly falling at sunset, while electricity demand is still high so making conventional generation essential for balancing the system.

All together, analyzing the selected hours in the two samples, we do not expect significant changes brought about by the introduction of RES generation at hour 3 , because both demand

\footnotetext{
${ }^{4}$ Actual load at national level has been collected from ENTSO-E, whereas, actual load for Northern Italy has been collected from Terna, which unfortunately provides these data only starting from 2010. Therefore, we used the latter data for comparing, across market sessions, costs determined in the second sample.
} 

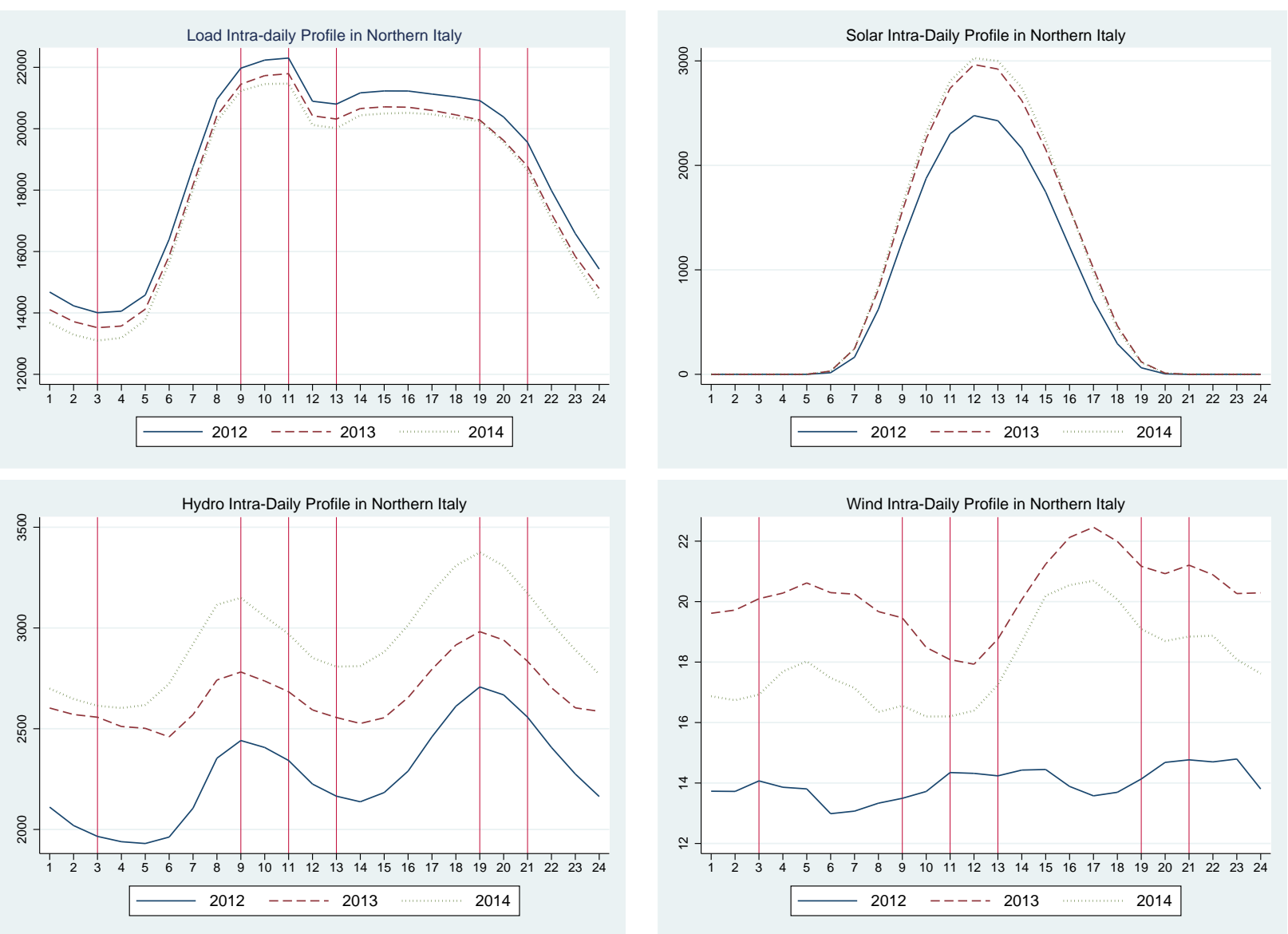

Figure 2: Intra-daily Profiles for Northern Zone and Selected Years.

and RES production are low. At hours 11 and 13, we expect a significant change brought about by RES-E, since demand is very high and RES generation is at its maximum (with the peak of solar production). At hour 19 we expect some changes because demand is still high, solar PV is low but wind is still contributing to the total generation. Considering different market sessions, we expect more relevant changes in day-ahead and a lower impact on balancing sessions, perhaps with different magnitudes at different hours. The analysis of balancing sessions is particularly interesting for explaining the behavior of balancing costs across samples.

Furthermore, to inspect the effect of fuels on electricity prices, brent crude oil, coal and ICE UK natural gas prices have been collected from Datastream, all converted in $€ / M W h$, whereas electricity day-ahead and balancing prices have been collected from $\mathrm{GME}^{5}$.

The analysis of the marginal technology index, MTI, (see Figure 10 in the Appendix) supports our decision to consider at the same time natural gas and oil $^{6}$. In fact, its inspection highlights the following facts that have to be considered for modeling purposes. First, turbo-

\footnotetext{
${ }^{5}$ Please visit www.mercatoelettrico.org and follow the instructions for downloads.

${ }^{6}$ For further discussion and analysis see Gianfreda and Grossi (2012).
} 
gas technology exhibits quite low percentages in determining the Northern zonal prices (from 0.27 observed during several hours and across most years, to 0.82 during hour 11 in 2013), and, for this reason, this technology has been merged with the predominant CCGT. Coal, natural gas as well as oil appear to be important fuel drivers (there are indeed several plants running with mixed fuels both in day-ahead and in balancing market sessions). Natural gas and oil have lost shares in the day-ahead market across the two samples and similarly water pumping, that lost shares in the second sample especially during ramp-up and ramp-down hours. Finally, foreign virtual zones and market coupling suddenly increased their shares.

Considering the planning and real-time horizons, we observe that RES-E reduces the production of conventional units, as renewable generation increases through years. This can be the main explanation of the reduced influence of fuels on electricity. Furthermore, we suppose that the general documented decrease of electricity demand over time (especially in the last years) must also correspond to a reduction in the electricity-fuel nexus, at least on the day-ahead horizon.

Taking into account the pay-as-bid pricing mechanism applied in real time auction sessions, we have computed the balancing prices weighted for the corresponding awarded quantities within each technology, hour, and day. We repeated this aggregation for purchases and sales awarded on the ex-ante MSD and MB sessions. Finally, we computed the weighted awarded prices using bids "accepted" on MSD and "not revoked" on $\mathrm{MB}^{7}$.

The preliminary analysis of prices and net trades (as difference between total awarded quantities on the demand and supply side) on the day-ahead, intra-day and balancing market sessions have been computed for all zones. The Northern zone of Italy is interestingly found to be in a persistent situation of "excess demand" after the closure of MGP market, without considering flows across national zones and foreign markets. In this situation, "up-regulating" power must be purchased during MSD and MB sessions ${ }^{8}$. This is clearly explained by Figure 3. where the dynamics of day-ahead electricity zonal prices ("MGP price" in the top left panel), together with the weighted prices observed on the first intra-day market session ("MI1 price" in the top right panel) and with the weighted MSD and MB prices (in both bottom left and right panels respectively) are represented with the corresponding net trades taking place at hour 11. After having inspected the long-run dynamics, we look at the prices awarded in balancing sessions at an high level of detail. We consider each single unit across market purpose and within a technology group, so that we are able to detect the maxima, minima and average prices for both purchases and sales. These data are obtained for each specific hour considered in the two sample periods. Tables 4 and 5 in the Appendix present full details. This analysis is actually important to detect market operators' changes in their bidding strategy.

The high level summary reported in Tables 1 and 2 helps in observing the following relevant facts for the Italian Northern zone. The average of yearly mean prices of each technology

\footnotetext{
${ }^{7}$ For this reason the data we use differ from prices computed and published by Terna for each ex-ante MSD sessions.

${ }^{8}$ In situations of up-regulation, Terna needs to buy electricity (the Italian chiamate a salire) for procuring power necessary to balance the system; in this case, she bears costs determined by 'sale' prices and quantities. On the contrary, in down-regulation Terna needs to sell electricity (the Italian chiamate a scendere) and she realizes profits determined by 'purchase' prices and quantities.
} 

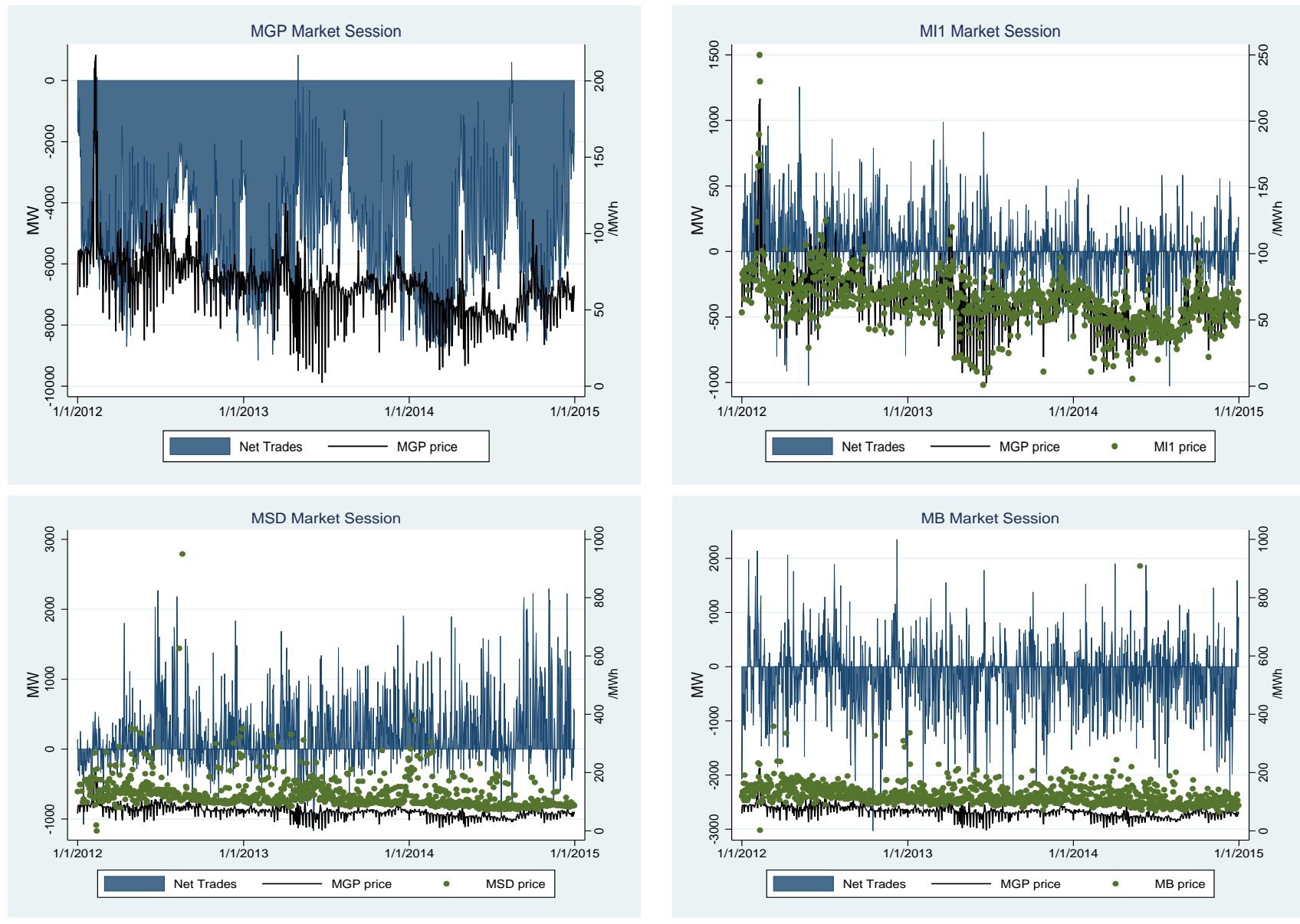

Figure 3: Net quantities during hour 11 in Northern Italy across MGP, MI, MSD and MB sessions respectively, together with corresponding weighted prices.

decreased across samples for both market sessions 9 for "purchases", with substantial differences for the MSD session (with reductions up to $23 € / M W h$ at hour 13). Different dynamics are instead observed for "sales", where we notice a decreasing trend for MSD mean prices opposite to the increasing trend of mean MB prices, for all hours but hour $3^{10}$ with reductions

\footnotetext{
${ }^{9}$ Specifically, we observed the following: at hour 3) 18 and $26 €$ /MWh on MSD and MB in the first sample, and they decreased respectively to 10 and $13 € / M W h$ on the second sample; at hour 9) 35 and 29 $€ / \mathrm{MWh}$ on MSD and MB in the first sample, and they decreased respectively to 17 and $22 € / \mathrm{MWh}$ on the second sample; at hour 11) 38 and $30 € /$ MWh on MSD and MB in the first sample, and 16 and $23 € / M W h$ on the second sample; at hour 13): 36 and $29 € /$ MWh on MSD and MB in the first sample, and 13 and 19 $€ / \mathrm{MWh}$ on the second sample; at hour 19) 37 and $31 € / \mathrm{MWh}$ on MSD and MB in the first sample, and 23 and $28 € / M W h$ on the second sample; finally, at hour 21) 36 and $30 € / M W h$ on MSD and MB in the first sample, and 20 and $29 € / \mathrm{MWh}$ on the second sample.

${ }^{10}$ In details, we observe the following: at hour 3), mean prices increase from 110 and $86 € /$ MWh on MSD and MB to 121 and $120 € /$ MWh in the second sample; at hour 9), the mean MSD price decreased from 141 to $124 € / \mathrm{MWh}$ whereas the mean MB price increased from 116 to $133 € / \mathrm{MWh}$; at hour 11), the mean MSD price decreased from 143 to $122 € / \mathrm{MWh}$ whereas the mean MB price increased from 113 to $125 € / \mathrm{MWh}$; at hour 13), the mean MSD price decreased from 138 to $118 € / M W h$ whereas the mean MB price increased from 118 to $122 € / \mathrm{MWh}$; at hour 19), the mean MSD price decreased from 139 to $132 € /$ MWh whereas the
} 
of up to $21 € /$ MWh on MSD and increases up to $34 € /$ MWh on MB. As for the maximum prices, they decreased in both MSD and MB market sessions for purchases ${ }^{11}$ with the highest reductions registered for thermal power (109€/MWh in MSD and $200 € / \mathrm{MWh}$ in $\mathrm{MB}$ at hour 11). Whereas, maximum prices registered for sales dramatically increased during MB sessions especially for hydro and thermal power. Data inspection clearly highlights a sort of coordinated and complementary bidding strategy for the two technologies. Hydro shows a dramatic increase in maximum prices at hours 11,19 and 21, with average increments of 1422, 1689 and $1922 € / \mathrm{MWh}$ in the second sample with respect to the first sample. On the contrary, thermal units set its maximum average price at hour 13, with a mean increment of $1717 € /$ MWh.

Our detailed analysis provides the empirical evidence of a strong and general increment of "sale" prices, observed over the second sample in balancing sessions, corresponding to the increasing RES penetration. On one side, more variable RES-E production might require more and careful balancing activities; on the other side, conventional operators are induced to explore market power opportunities increasing their prices on the balancing session (which is a structurally concentrated market) to recover profits lost on the day-ahead session.

\begin{tabular}{|c|c|c|c|c|c|c|c|c|c|c|c|c|}
\hline \multirow[b]{3}{*}{ Hour } & \multicolumn{4}{|c|}{ Hydro } & \multicolumn{4}{|c|}{ Water Pumping } & \multicolumn{4}{|c|}{ Thermal } \\
\hline & \multicolumn{2}{|c|}{ Max } & \multicolumn{2}{|c|}{ Mean } & \multicolumn{2}{|c|}{ Max } & \multicolumn{2}{|c|}{ Mean } & \multicolumn{2}{|c|}{ Max } & \multicolumn{2}{|c|}{ Mean } \\
\hline & MSD & MB & MSD & $\mathrm{MB}$ & MSD & $\mathrm{MB}$ & MSD & MB & MSD & MB & MSD & MB \\
\hline 3 & $\downarrow 10$ & $\uparrow 28$ & $\downarrow 8$ & $\uparrow 9$ & $\uparrow 8$ & $\downarrow 24$ & $\downarrow 12$ & $\downarrow 14$ & $\downarrow 38$ & $\downarrow 128$ & $\downarrow 3$ & $\downarrow 32$ \\
\hline 9 & $\downarrow 84$ & $\uparrow 30$ & $\downarrow 37$ & $\longleftrightarrow$ & $\downarrow 1$ & $\downarrow 55$ & $\downarrow 23$ & $\downarrow 15$ & $\downarrow 86$ & $\downarrow 178$ & $\uparrow 3$ & $\downarrow 6$ \\
\hline 11 & $\downarrow 73$ & $\downarrow 44$ & $\downarrow 43$ & $\downarrow 4$ & $\downarrow 1$ & $\downarrow 72$ & $\downarrow 28$ & $\downarrow 18$ & $\downarrow 109$ & $\downarrow 200$ & $\uparrow 5$ & $\longleftrightarrow$ \\
\hline 13 & $\downarrow 82$ & $\downarrow 57$ & $\downarrow 40$ & $\downarrow 9$ & $\downarrow 16$ & $\downarrow 64$ & $\downarrow 34$ & $\downarrow 18$ & $\downarrow 72$ & $\downarrow 190$ & $\uparrow 4$ & $\downarrow 3$ \\
\hline 19 & $\downarrow 64$ & $\downarrow 72$ & $\downarrow 32$ & $\downarrow 3$ & $\downarrow 3$ & $\downarrow 36$ & $\downarrow 17$ & $\downarrow 7$ & $\downarrow 94$ & $\downarrow 201$ & $\uparrow 9$ & $\uparrow 1$ \\
\hline 21 & $\downarrow 62$ & $\downarrow 28$ & $\downarrow 30$ & $\uparrow 5$ & $\downarrow 16$ & $\downarrow 46$ & $\downarrow 26$ & $\downarrow 7$ & $\downarrow 98$ & $\downarrow 201$ & $\uparrow 10$ & $\longleftrightarrow$ \\
\hline
\end{tabular}

Table 1: High level summary dynamics across samples for the average Maximum and Mean Prices awarded for "Purchases" on MSD and MB across hours and technologies, where $\uparrow, \downarrow$ and $\leftrightarrow$ represent an average increment, decrement or no changes across the two samples measured by the corresponding amounts expressed in $€ / M W h$.

We have also examined the total balancing quantities per hours, years and market purpose. The amount of balancing quantities (expressed in MW) is computed as sum from the corresponding awarded quantities on MSD and MB. In details, only "non revoked" bids have been considered in our analysis firstly because those "revoked" and "of netting" represent only small percentages over the total of auctions ${ }^{12}$ and, secondly, because the indication about the type was not available in our first sample 2006-2008.

mean MB price increased from 117 to $129 € / \mathrm{MWh}$; finally, at hour 21, the mean MSD price decreased from 137 to $128 € / \mathrm{MWh}$, whereas the mean MB price increased from 120 to $133 € / \mathrm{MWh}$.

${ }^{11}$ There are only few exceptions: MB maximum prices at hour 3 and 9 increased for hydro, and MSD maximum prices increased at hour 3 for water pumping.

${ }^{12}$ The preliminary analysis of the balancing market sessions shows how the percentages of total accepted quantities on MB were: 1) for "revoked" auctions only $6 \%$ in 2013, $7 \%$ in 2014 and $5 \%$ in 2015 for purchases, whereas for sales 7\%, 6\% and 7\% in 2013, 2014 and 2015; 2) for "netting" auctions only $2 \%$ in 2013 and 2014, and 1\% in 2015 for purchases, whereas for sales $6 \%$ in 2013 and $8 \%$ in 2014 and 2015 . Then, this 


\begin{tabular}{cllllllllllll}
\hline \hline & \multicolumn{4}{c}{ Hydro } & \multicolumn{4}{c}{ Water Pumping } & \multicolumn{4}{c}{ Thermal } \\
\cline { 2 - 13 } Hour & \multicolumn{3}{c}{ Max } & \multicolumn{2}{c}{ Mean } & \multicolumn{2}{c}{ Max } & Mean & \multicolumn{3}{c}{ Max } & Mean \\
\hline & MSD & MB & MSD & MB & MSD & MB & MSD & MB & MSD & MB & MSD & MB \\
\hline 3 & $\downarrow 20$ & $\uparrow 111$ & $\downarrow 3$ & $\uparrow 8$ & $\uparrow 19$ & $\uparrow 67$ & $\uparrow 36$ & $\uparrow 63$ & $\uparrow 148$ & $\uparrow 884$ & $\downarrow 3$ & $\uparrow 31$ \\
9 & $\downarrow 54$ & $\uparrow 176$ & $\downarrow 33$ & $\downarrow 31$ & $\uparrow 19$ & $\uparrow 57$ & $\uparrow 11$ & $\uparrow 37$ & $\uparrow 48$ & $\uparrow 30$ & $\downarrow 28$ & $\uparrow 45$ \\
11 & $\downarrow 12$ & $\uparrow 1422$ & $\downarrow 44$ & $\downarrow 20$ & $\uparrow 34$ & $\uparrow 55$ & $\uparrow 15$ & $\uparrow 34$ & $\uparrow 38$ & $\uparrow 25$ & $\downarrow 34$ & $\uparrow 21$ \\
13 & $\downarrow 46$ & $\uparrow 13$ & $\downarrow 28$ & $\downarrow 31$ & $\uparrow 25$ & $\uparrow 39$ & $\longleftarrow$ & $\uparrow 28$ & $\uparrow 35$ & $\uparrow 1717$ & $\downarrow 34$ & $\uparrow 17$ \\
19 & $\uparrow 22$ & $\uparrow 1689$ & $\downarrow 22$ & $\downarrow 24$ & $\uparrow 48$ & $\uparrow 60$ & $\uparrow 35$ & $\uparrow 40$ & $\downarrow 11$ & $\uparrow 903$ & $\downarrow 33$ & $\uparrow 18$ \\
21 & $\downarrow 41$ & $\uparrow 1922$ & $\downarrow 28$ & $\downarrow 23$ & $\uparrow 43$ & $\uparrow 55$ & $\uparrow 36$ & $\uparrow 42$ & $\downarrow 50$ & $\uparrow 379$ & $\downarrow 34$ & $\uparrow 18$ \\
\hline \hline
\end{tabular}

Table 2: High level summary dynamics across samples for the average Maximum and Mean Prices awarded for "Sales" on MSD and MB across hours and technologies, where $\uparrow, \downarrow$ and $\leftrightarrow$ represent an average increment, decrement or no changes across the two samples measured by the corresponding amounts expressed in $€ /$ MWh.

The yearly dynamics of awarded quantities across MSD and MB sessions in Northern Italy are presented in Figure 4. We can notice that purchased quantities dramatically reduced in the MSD planning sessions during the second sample, whereas awarded quantities slightly increased in MB at hours 9 and 11. Moving to sold quantities (hence looking at the last two panels), we find an opposite dynamics: these quantities increased in MSD whereas decreased in MB for all peak hours. We observe a common decreasing trend in both MSD and MB sessions at hour 3 and at hour 21, which, on the contrary, is characterized by increments in 2015 (especially in MSD). Furthermore, it is interesting to observe that water pumping heavily lost market shares in MB during the second sample. We explain the latter finding referring to the impact of RES on the intra-daily profile of the day-ahead market price: it can be noticed that the spread between maximum and minimum prices has decreased substantially from the first to the second sample ${ }^{13}$. Since water pumping units buy electricity off-peak and then sell it during peak hours, the new intra-daily profile of zonal prices makes this technology less competitive as the spread diminishes.

Therefore, we can easily assess that the introduction of RES-E corresponds to an overall reduction of quantities sold to Terna for balancing purposes, hence supporting the findings in Hirth and Ziegenhagen (2015). For this reason, and in line with other studies, we observe that the strong increment of RES did not require more balancing, which is a quite unexpected result. However, since balancing costs depends also on prices (which are part of the accepted bids submitted by balancing operators), we can observe increasing costs despite decreasing quantities due to producers' behavior. We calculate these balancing costs in Section 4.3.

\subsection{Methods}

We first aim at studying the evolution of the long-run dynamics between fuels prices. This allows us to identify the driving forces of electricity prices before exploring the influence

classification of balancing "type" of auctions introduced after 2009 may induce some overestimation of our balancing costs in the second sample, but we believe that it is negligible.

${ }^{13}$ See Figure 11 in the Appendix where a flatter dynamics of the intra-daily profiles of zonal prices can be observed in the second sample of years. 

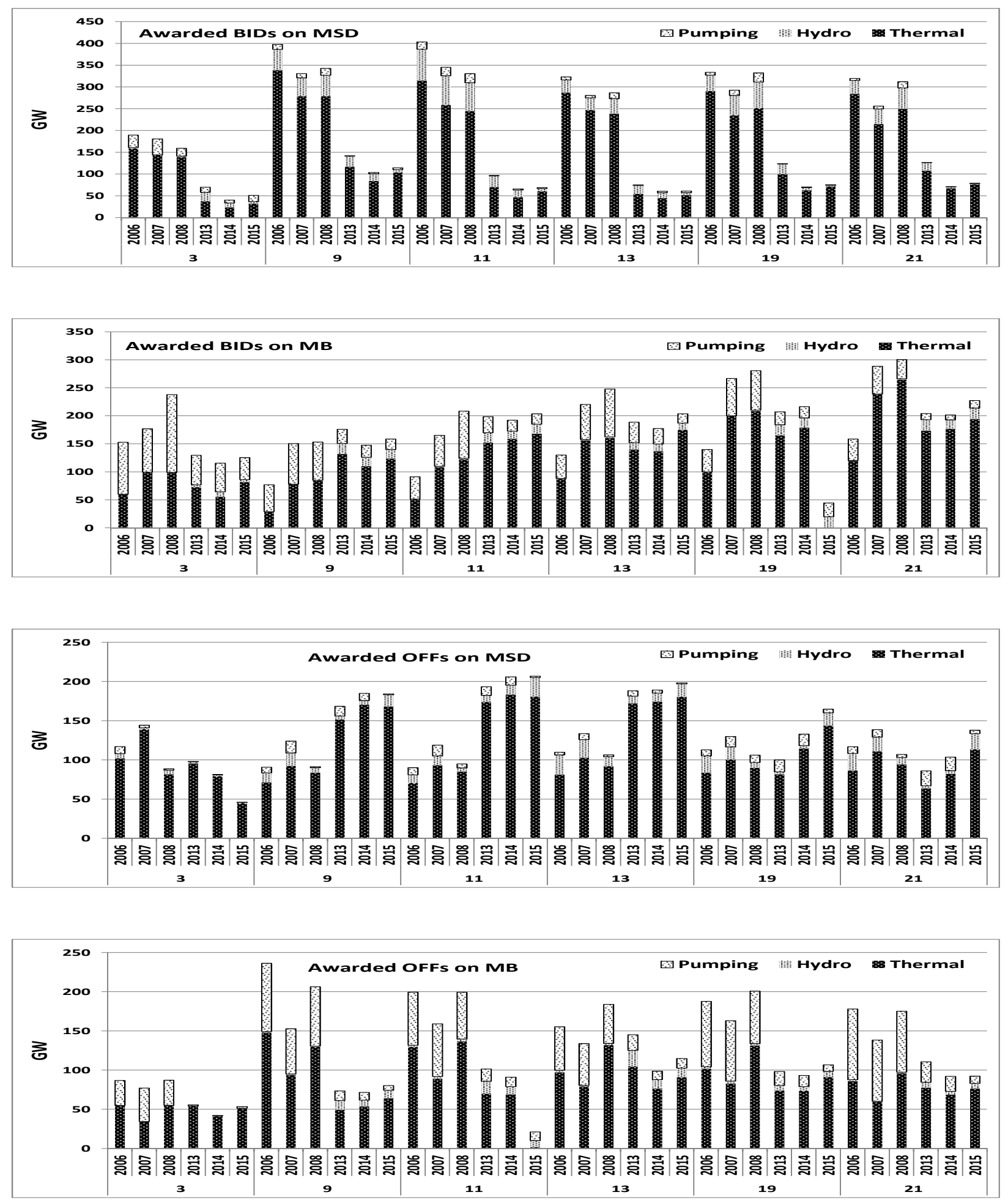

Figure 4: Yearly Sum of Awarded Purchased ('Bids' on the first two rows) and Offered or "Sold" ('Offs' on the last two rows) Quantities on MSD and MB balancing market sessions in Northern Italy, across technologies, selected hours and years. 
of RES on the fuels-electricity nexus at day-ahead and balancing levels. Secondly, we quantify exactly the costs incurred by balancing needs induced by increasing RES generation. Therefore, we have pre-processed our time series to undertake the first analysis by means of vector error correction models (VECM) and forecast error variance decomposition (FEVD), as described below.

\subsubsection{Price Pre-processing}

It is a well known fact that wholesale electricity prices are very far from behaving like Gaussian processes (Bottazzi et al., 2005; Bosco et al., 2010) and, thus, least-squares based econometric methods tend to fail. Furthermore, the data generating process of electricity prices can be viewed as the sum of a persistent component linked to the marginal costs of production and affected by the market structure plus an extremely noisy and leptokurtic component determined by short-term "shocks" such as strategies of the market participants, mismatch between the actual demand and its forecasts, plant maintenance, exceptional meteorological events, etc.

Before analyzing the (Granger) causal relations between electricity and fuel prices, we need to clean the daily time series of electricity from components such as seasonal periodicities and additive outliers that are not present in fuel prices. In other analyses like Bosco et al. (2010) and Gianfreda et al. (2016b) we took care of these components by reducing the frequency of the time series using weekly means or medians, but since Italian electricity prices are heavily affected also by a 365-day periodic component and fuel prices may have also short-term effect on electricity prices, in this work we decided to keep all the time series at their original (daily) frequency and annihilate the components that could partially hide or alter the causal relationships between the time series.

The data pre-processing ${ }^{14}$ is conducted on the basis of the following steps.

1. Estimate the unobserved component model (UCM) $y_{t}=\mu_{t}+\gamma_{t}+\theta_{t}+\varepsilon_{t}$, where $\mu_{t}$ is as a random walk, $\gamma_{t}$ is a time-varying periodic spline component with a 365-day period, $\theta_{t}$ is a time-varying trigonometric seasonal component with a 7 -day period and $\varepsilon_{t}$ is a white noise ${ }^{15}$.

2. Identify all the additive outliers by using the auxiliary residuals relative to the observation error sequence $\varepsilon_{t}$.

3. Estimate the same UCM adding one dummy regressor for each additive outlier identified in the previous step (alternatively, the observations identified as outliers can be set to missing).

4. Compute the outlier- and seasonality-free time series as $\hat{y}_{t}=\hat{\mu}_{t \mid n}+\hat{\varepsilon}_{t \mid n}$, where $\hat{\mu}_{t \mid n}$ and $\hat{\varepsilon}_{t \mid n}$ are obtained by running the state smoother on the respective components using the UCM of the previous step.

\subsubsection{Methodology: VECM and FEVD}

All time series of the logarithm of electricity, coal and gas prices were tested for a unit root and stationarity using the ADF and KPSS tests over the full sample 2006-2015, and the

\footnotetext{
${ }^{14}$ These computations were carried out using the PROC UCM of SAS/ETS. The code is provided as supplementary material.

${ }^{15}$ See Harvey and Koopman (1993) and Pelagatti (2015).
} 
conclusion is that all time series are integrated of order one (i.e., I(1)). Since our conjecture is that the strong increment of RES generation induced changes in the relation between electricity and fuel prices, all the following analyses have been carried out separately on the two subsamples.

In the first step of the analysis we considered the vector of time series containing the log-prices of gas, oil and coal in the two subsamples. For each subsample, we determined the order of the VAR using the Akaike (AIC) and the Hannan-Quinn (HQC) information criteria and tested for the order of cointegration using Johansen's sequential test. While the two information criteria in one case suggested a different order of the VAR, the conclusions about the number of cointegrating relations were robust to the different VAR orders: one cointegrating relation in the first sample and no cointegration for the second one. The forecast error variance decomposition (FEVD) generated by VECMs estimated on the two subsamples are depicted in Figure 5.

The same procedure was applied to the vector containing the fuel prices and the day-ahead prices and to the vector containing the fuel prices and the balancing prices. Each electricity price time series was added individually to the fuel price vector, so that the VAR/VECMs we estimated were always four-dimensional. The results are summarized in Table 3 . Notice that we report only one cointegration rank for each model because Johansen's test selected always the same number of cointegrating relations under both AIC- and HQC-based VAR orders. The main message of Table 3 is that the number of cointegrating relations reduced from 2 to 1 both for day-ahead prices and balancing prices. This finding is coherent with the analogous result we had for the vector of fuel time series, which were cointegrated in the first sub-sample and not cointegrated in the second one. Thus, even though the fuel time series in the second sample evolve with distinct trends, there is a long run equilibrium that keeps fuel prices and electricity prices aligned. A detailed analysis of the long run effects of unexpected shocks in fuel prices on electricity prices can be carried out observing the FEVD plots in Figure 6. ${ }^{16}$ The rest of this section is devoted to the analysis and interpretation of these FEVD plots.

\subsection{Empirical Results}

4.3.1. The nexus across Fuels: studying Crude Oil, Natural Gas and Coal prices

The result that the cointegrating relation observed among fuel prices in the first sample vanishes in the second sample is consistent with the findings of Erdös (2012), who shows that US oil and gas prices have decoupled since January 2009. Before 2009, US and UK gas prices had a long-term equilibrium with crude prices to which gas prices always reverted after exogenous shocks. This result may be partially due to the fact that in the past gas contracts were often indexed using moving averages of oil prices (generally 3 to 6 months long), while in the last years gas markets have become more liquid and gas prices started to follow their own trends not necessarily linked to those of oil and coal.

Figure 5 shows the FEVD of coal, natural gas and crude oil over 350 days to determine how much of the fuels' price variance can be explained by exogenous shocks hitting the other variables. It is clear from the top row that the influence of oil price on gas and coal prices

\footnotetext{
${ }^{16}$ Computations covered in this subsection have been carried out using the open-source econometric package Gretl (http://gretl.sourceforge.net/).
} 


\begin{tabular}{|c|c|c|c|c|c|c|c|}
\hline & \multirow[b]{2}{*}{ Hour } & \multicolumn{3}{|c|}{ Day Ahead } & \multicolumn{3}{|c|}{ Balancing Market } \\
\hline & & $\begin{array}{l}\text { Lags } \\
\text { (AIC) }\end{array}$ & $\begin{array}{c}\text { Lags } \\
\text { (HQC) }\end{array}$ & $\begin{array}{l}\text { Coint. } \\
\text { Rank }\end{array}$ & $\begin{array}{l}\text { Lags } \\
\text { (AIC) }\end{array}$ & $\begin{array}{c}\text { Lags } \\
\text { (HQC) }\end{array}$ & $\begin{array}{l}\text { Coint. } \\
\text { Rank }\end{array}$ \\
\hline \multirow{6}{*}{ First Sample } & 3 & 4 & 2 & 2 & 3 & 2 & 2 \\
\hline & 9 & 3 & 2 & 2 & 3 & 3 & 2 \\
\hline & 11 & 3 & 2 & 2 & 3 & 2 & 2 \\
\hline & 13 & 3 & 3 & 2 & 3 & 2 & 2 \\
\hline & 19 & 3 & 3 & 2 & 3 & 2 & 2 \\
\hline & 21 & 2 & 2 & 2 & 3 & 2 & 2 \\
\hline \multirow{6}{*}{ Second Sample } & 3 & 3 & 3 & 1 & 3 & 1 & 1 \\
\hline & 9 & 3 & 3 & 1 & 3 & 3 & 1 \\
\hline & 11 & 6 & 3 & 1 & 3 & 3 & 1 \\
\hline & 13 & 5 & 3 & 1 & 6 & 3 & 1 \\
\hline & 19 & 6 & 3 & 1 & 6 & 3 & 1 \\
\hline & 21 & 5 & 3 & 1 & 3 & 1 & 1 \\
\hline
\end{tabular}

Table 3: Results of the lag-selection procedure and Johansen's cointegration test applied to the vector of time series containing the log-prices of gas, coal, oil and electricity at each considered hour.

was dominant in the first sample, whereas from the bottom row of figures we see that this influence did not vanish completely but was significantly reduced in the second sample. We think that the decreased influence of oil on natural gas prices can be partly explained by the changing generation mix since it has been documented over the sample of years characterized by high RES penetration. We analyze in depth the relationship among fuels and electricity prices in the next Subsection 4.3.2.
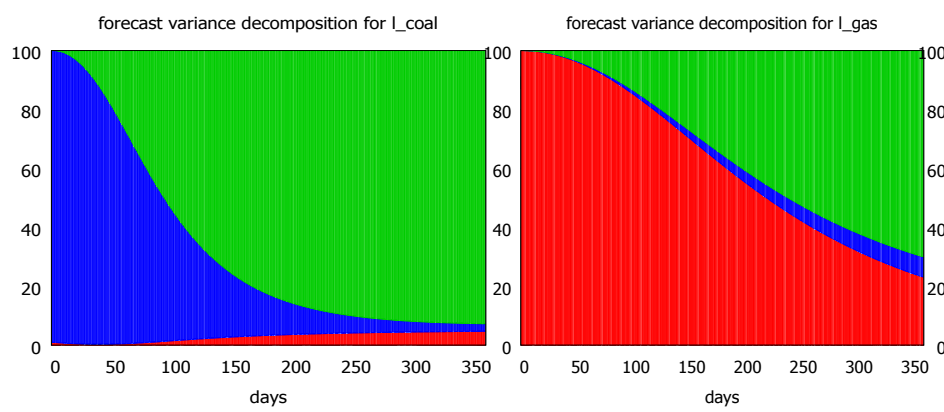

forecast variance decomposition for __oil

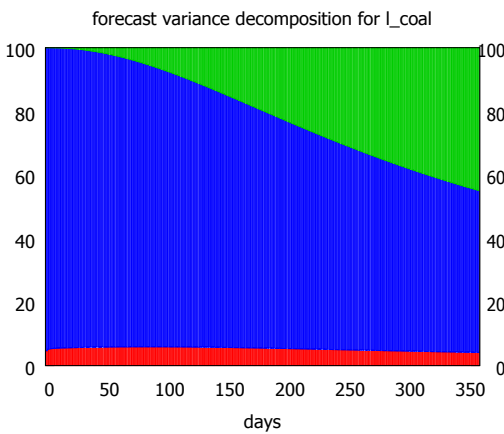

forecast variance decomposition for I_gas

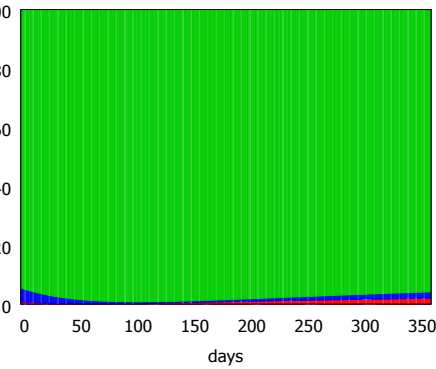

I_gas $\square$

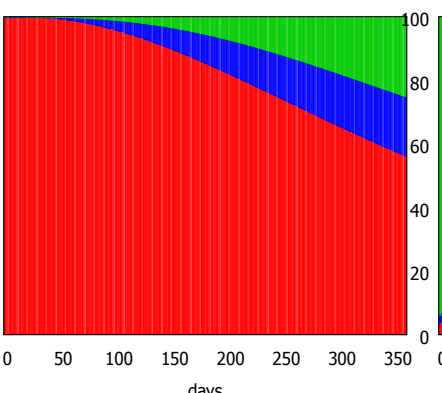

forecast variance decomposition for __oil

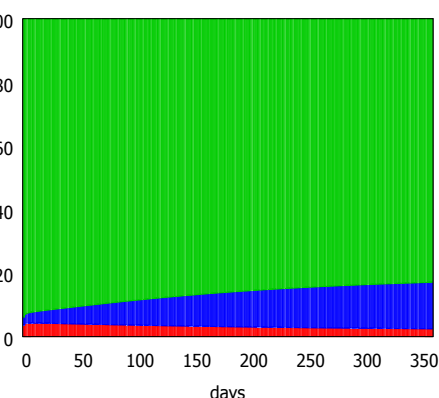

I_gas

Loil

Figure 5: Forecast error variance decomposition of coal, natural gas and brent crude oil over 350 days for the sample 2006-2008 on the first row, and the sample 2013-2015 on the second row. 


\subsubsection{The Electricity-Fuels Nexus: comparing day-ahead and balancing levels}

Given the dynamics on the international markets characterized by lower coal prices and high US natural gas supply, we expect more coal consumption in the EU and, more generally, coal playing a leading role in the determination of day-ahead electricity prices, even though natural gas may exercise its influence on balancing prices. At the same time, the evolving generation mix due to increasing RES penetration suggests us to implement a dynamic analysis over two samples characterized by different share of RES. Controlling for demand, we expect that the changes in the dynamics of day-ahead electricity prices are mainly driven by the increase in RES generation, which has forced conventional units to trade more into balancing and much less into day-ahead sessions. We, therefore, expect that conventional generation, and hence the associated fuels, decreases its influence on day-ahead prices but affects substantially balancing prices.

To this aim, we have decomposed the forecast variance of electricity day-ahead and balancing prices in terms of forecast variance of coal, oil and gas prices, looking at specific hours or levels of demand. In this way, we are able first to explore the evolution of the relationship between both types of electricity prices and the prices of hydrocarbon resources, and secondly to establish their importance in determining the electricity prices in the long run. Results for hours 3, 13 and 21 are depicted ${ }^{17}$ in Figure 6. Day-ahead prices are considered on the left column and balancing prices on the right column. Even rows show figures for the sample 2006-08, whereas odd rows report results for period 2013-15. As we expected, the most striking results are obtained for the day-ahead market sessions. In all hours we notice a strong reduction in the influence of gas prices in explaining the dynamic behavior of electricity prices. More generally, fuels maintain their relevance in determining movements of electricity prices, but now coal appears to have a leading role among fuels. Balancing sessions show a less pronounced change. First, fuels maintain the same relevance in determining the dynamics of prices across the two samples and they appear to be less important with respect to day-ahead sessions (FEVD indicates that more $60 \%$ of electricity prices variance is explained by unexpected shocks on fuels in day-ahead session but only around $20 \%$ in balancing sessions). Secondly, shares of fuels exhibit only slight changes; at hour 21 we observe an increase in the role of coal but of limited magnitude.

The fact that the shares of fuels remain similar in balancing sessions across the two samples, while they substantially decreased in the MGP, confirms the intuition of evolving profit opportunities across market sessions. Since gas-fired plants lose a large share into the day-ahead market, then they are forced to move towards balancing. The most interesting insight emerging from our findings is that RES have pushed conventional units (those allowed) towards balancing sessions, where we observe a more fragmented (because of the 'switching' across fuels) but consistent influence of oil, gas and coal on electricity prices; and in what follows, we quantify this 'RES-induced switching effect' across fuels by computing the cost of balancing energy.

To summarize, hydrocarbon price movements are much less relevant in determining both day-ahead and balancing electricity prices for the sample 2013-2015, whereas the greatest

\footnotetext{
${ }^{17}$ Similar results, found for the remaining hours, have not been presented for lack of space; but they are available on request.
} 
part of the electricity price variances in 2006-2008 were determined by changes in gas prices for day-ahead, and by gas and coal price movements for balancing prices. In the former case, we ascribe this evidence to the high level of RES penetration, in combination with the dynamics of demand. In the latter case, the low impact of fuels on balancing prices can be easily explained given that many other important facts influence the prices determined at real time: indeed our analysis of prices explicitly focuses on fuel drivers and thus it omits forecasting errors in demand, in wind and solar PV generations, availability of reserve capacity, and import/export flows, among others. Nonetheless, it is important to understand the actual balancing costs induced by RES generation. 

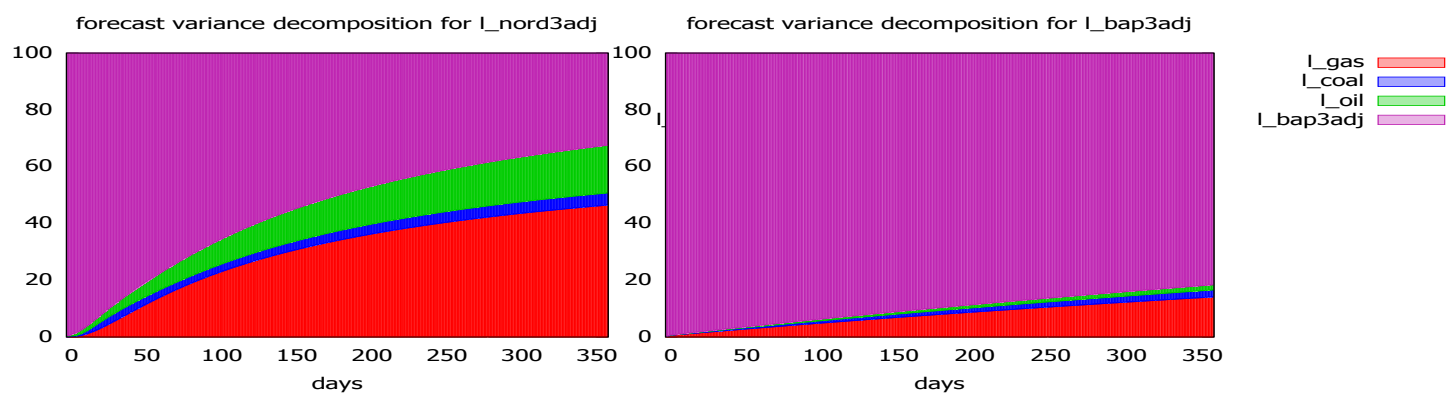

forecast variance decomposition for I_nord3adj

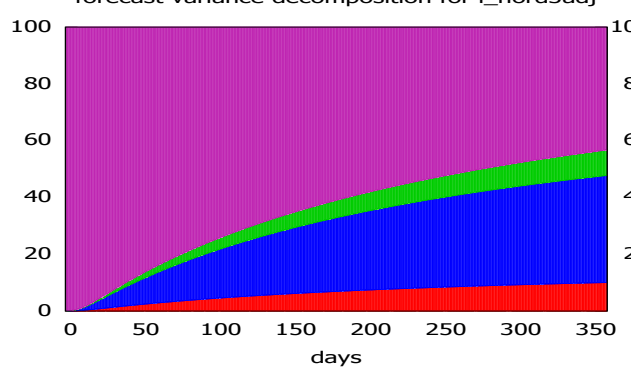

forecast variance decomposition for I_bap3adj
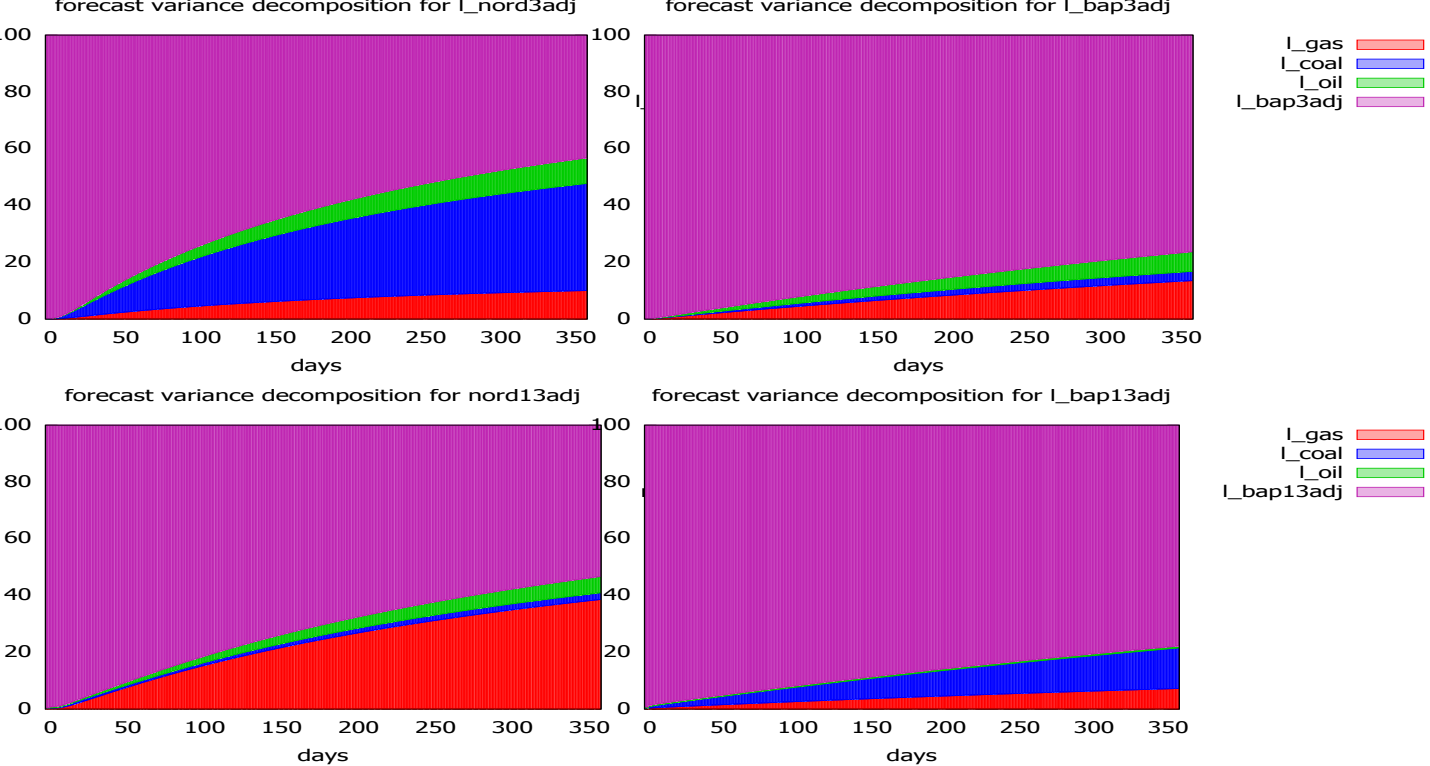

forecast variance decomposition for I_bap13adj
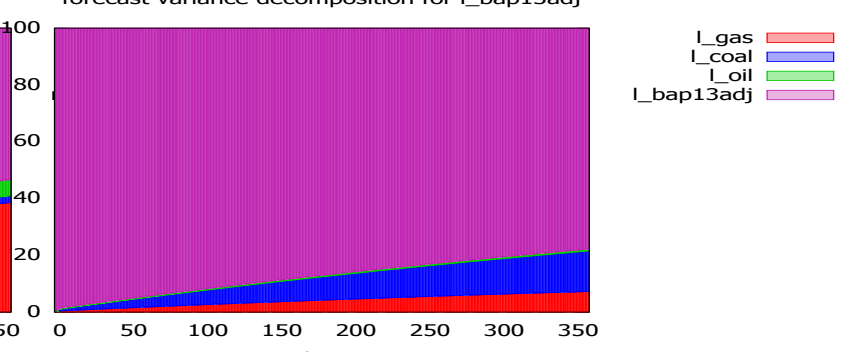

forecast variance decomposition for nord13adj

forecast variance decomposition for I_bap13adj
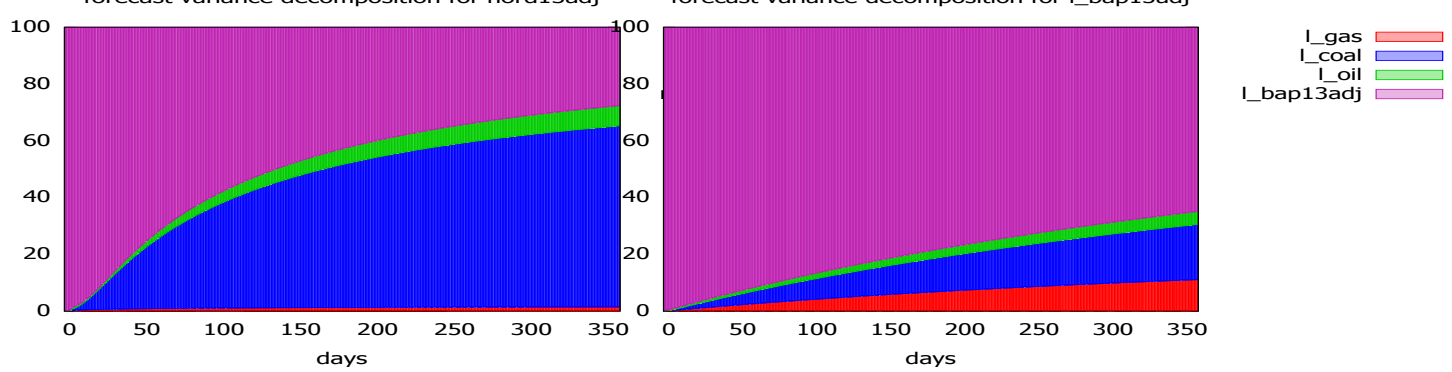

forecast variance decomposition for nord21adj

forecast variance decomposition for I_bap21adj
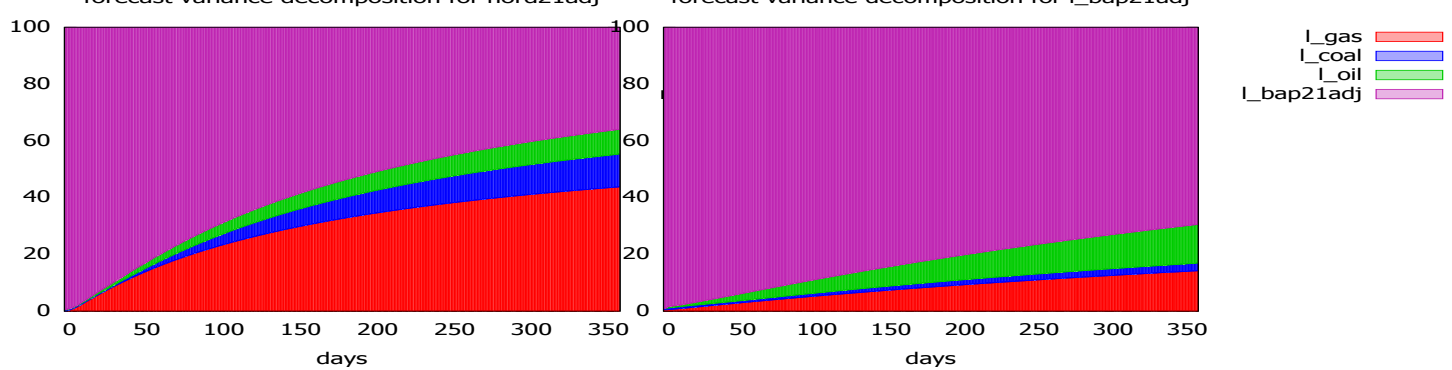

forecast variance decomposition for I_nord21adj
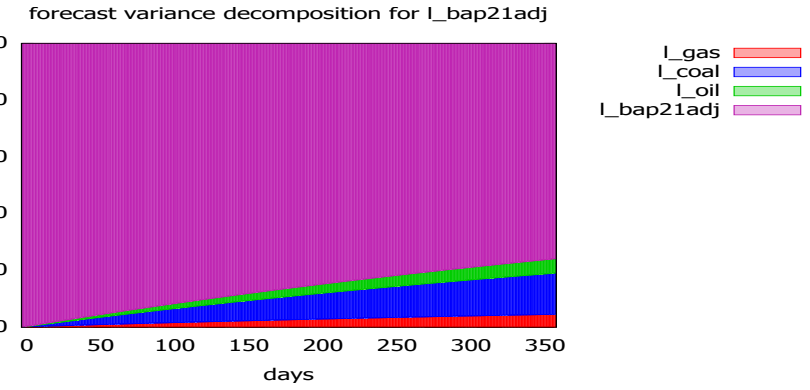

Figure 6: Variance Decomposition for Northern Italian day-ahead (and the left) and balancing (on the right) prices at hours 3 (on rows 1-2), 13 (rows 3-4) and 21 (rows 5-6), on sample 2006-2008 on odd rows and on sample 2013-2015 on even rows respectively. 


\subsubsection{Quantification of Balancing Costs}

The quantification of costs incurred for planning and dispatching balancing power has very interesting policy implications, especially after the recent judgment of the Italian Administrative Court (TAR, 28 June 2016) that, following the complaint of one consumers' association, canceled the tariff increase established by the AEEGSI. The increment of 4.3\% in the electricity bill was motivated by higher energy market prices registered in the preceding months, with particular reference to the balancing sessions. Consumers complained an alleged strategic sellers' behavior which induced a significant cost increase in dispatching services.

To analyze this issue, we first compute the actual balancing costs multiplying the awarded prices for corresponding awarded quantities at unit level; then, we aggregate the information across technologies, hours, years and market purpose. As before, by "sales" we mean situations in which Terna buys quantities incurring in 'costs' for the system, and so for final consumers (these are represented with negative values); whereas by "purchases" we mean situations in which Terna sells quantities obtaining instead 'profits' (depicted with positive values).

Focusing only on two components ${ }^{18}$ of the uplift, we study profits and costs for hydro, water pumping and thermal power respectively, considering both the ex-ante MSD and MB sessions. In Figure 7, we can observe that profits from hydro and water pumping dramatically decreased for all hours over the second sample, whereas we observe moderate reductions when thermal power is considered. In particular, we find that costs decreased substantially in the second sample, when Terna bought electricity from water pumping. On the contrary, there is an unclear overall trend for hydro and thermal power, with a noticeable increment of costs in 2015 with respect to 2014. Furthermore, the majority of hydro allocations are observed into MSD sessions, whereas water pumping costs are mainly based into MB sessions. Costs of thermal power are spread on both MSD and MB sessions, where we observe sustained costs across years, again with significant increase from 2014 to 2015 especially at hours 19 and 21. This result is particularly relevant since the solar production suddenly decreases at evening and thermal units become necessary to the system and able to exploit a high degree of market power. Therefore, we find evidence that the increase in balancing prices is originated from operators' bidding strategies in hours when they enjoy a high degree of market power.

Starting from this detailed analysis, we are able to quantify the overall profits/costs, as sum across technologies on both market sessions within a year. Results, reported in Figure 8. show that Terna was making the majority of profits on the ex-ante MSD in the first sample and on the MB in the second sample. Costs were almost equally spread between the two market sessions (with higher shares in MSD than in MB, apart at hour 9 when MB costs represented $69 \%$ of average costs in the second sample). The planning activity executed in MSD is actually a substantial part of computed costs and a migration towards a capacity market may be of help for the system. Finally, we compute the overall balance as the difference between profits and costs, faced by the Italian TSO for the Northern zone. In Figure 9, we clearly observe that the activities of planning resources and dispatching

\footnotetext{
${ }^{18}$ The first component is the planning of services which concerns the ex-ante MSD sessions, and the second one is the energy component which takes into account all the realized imbalances. See Section 3 for details.
} 

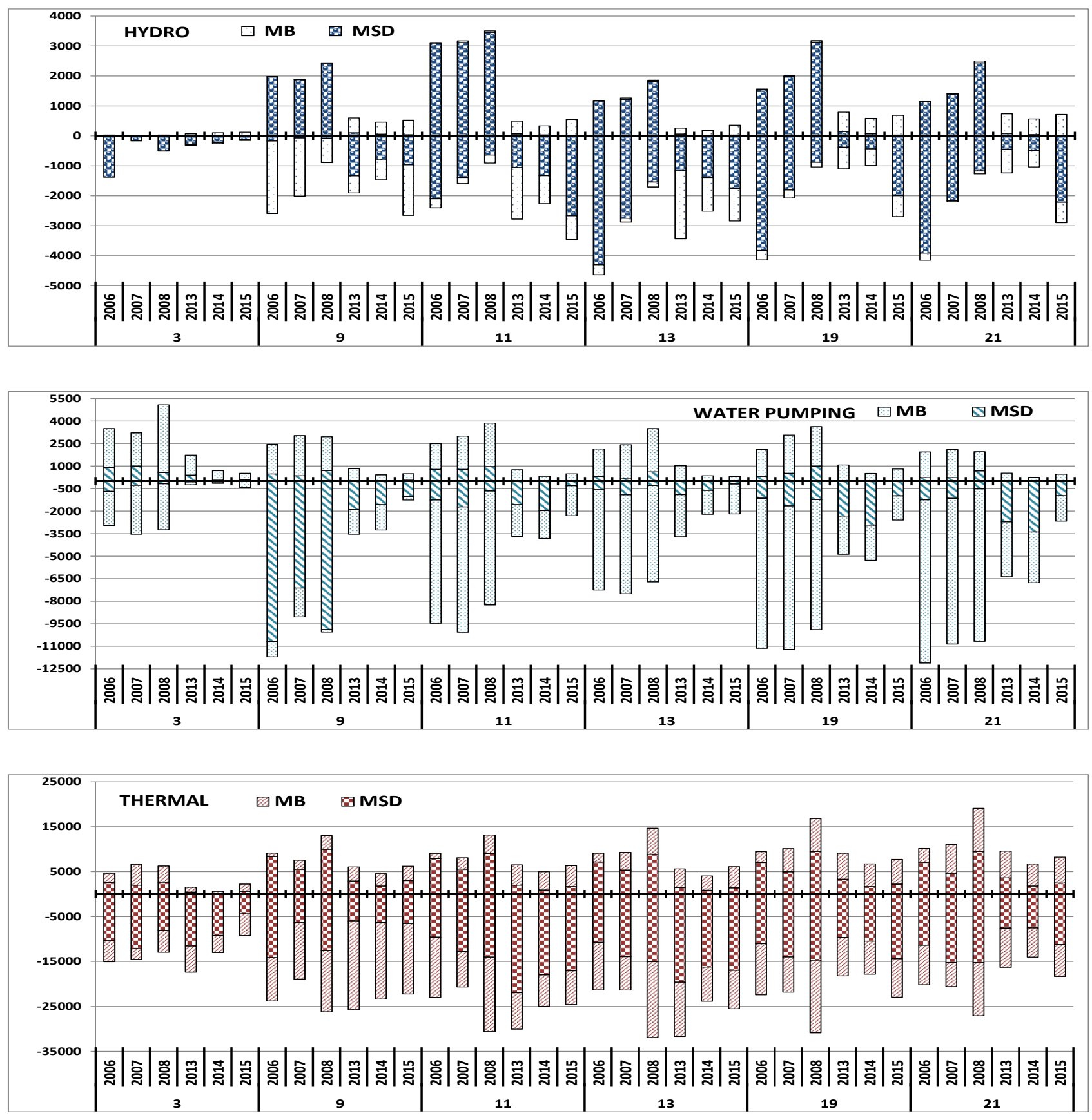

Figure 7: Evolution of balancing costs (in thousands of $€$ ) in Northern Italy across years and selected hours for Hydro (on the first row), Water Pumping (on the second row) and Thermal Power (on the third row) distinguishing between profits (purchases from Terna) and costs (sales or offers to Terna).

balancing power are highly costly. The average costs increased in the second sample at hours $3,9,11$ and 13 and we observe the highest average costs at hour 13 equal to 26.5 


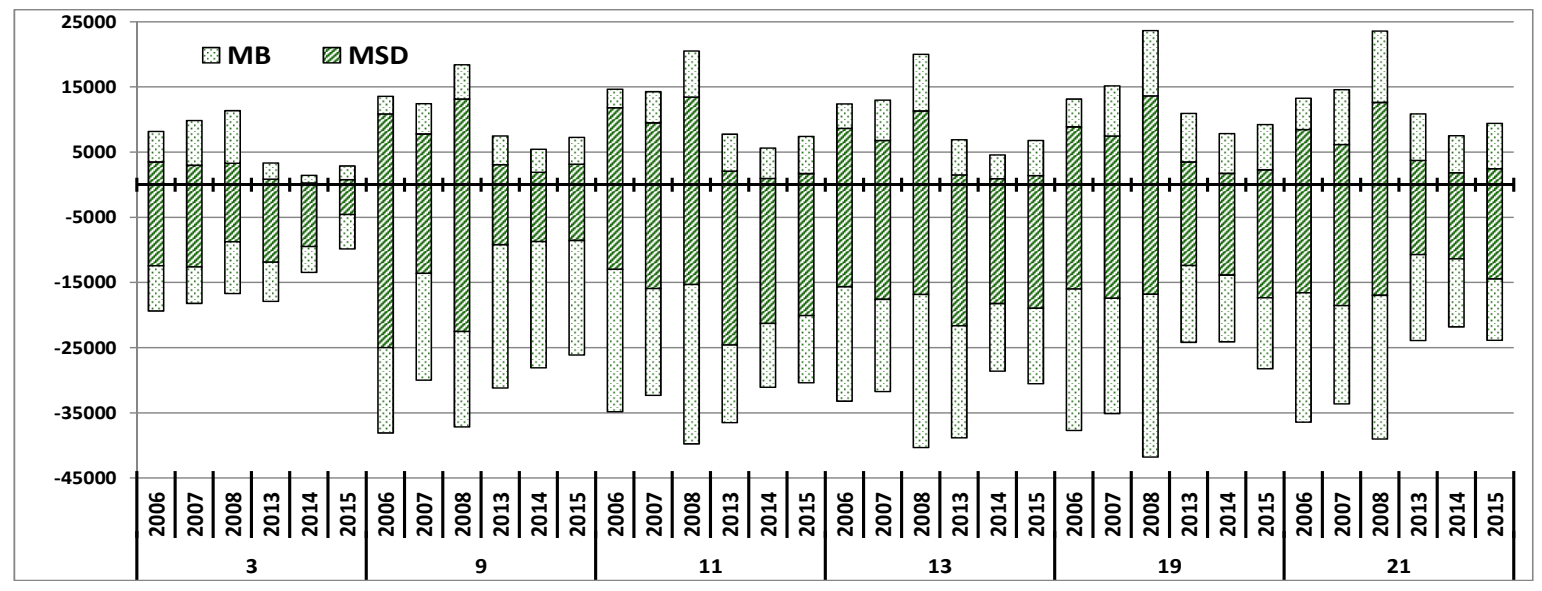

Figure 8: Evolution of Profits and Costs (as sums across technologies, in thousands of $€$ ) on MSD and MB in Northern Italy.

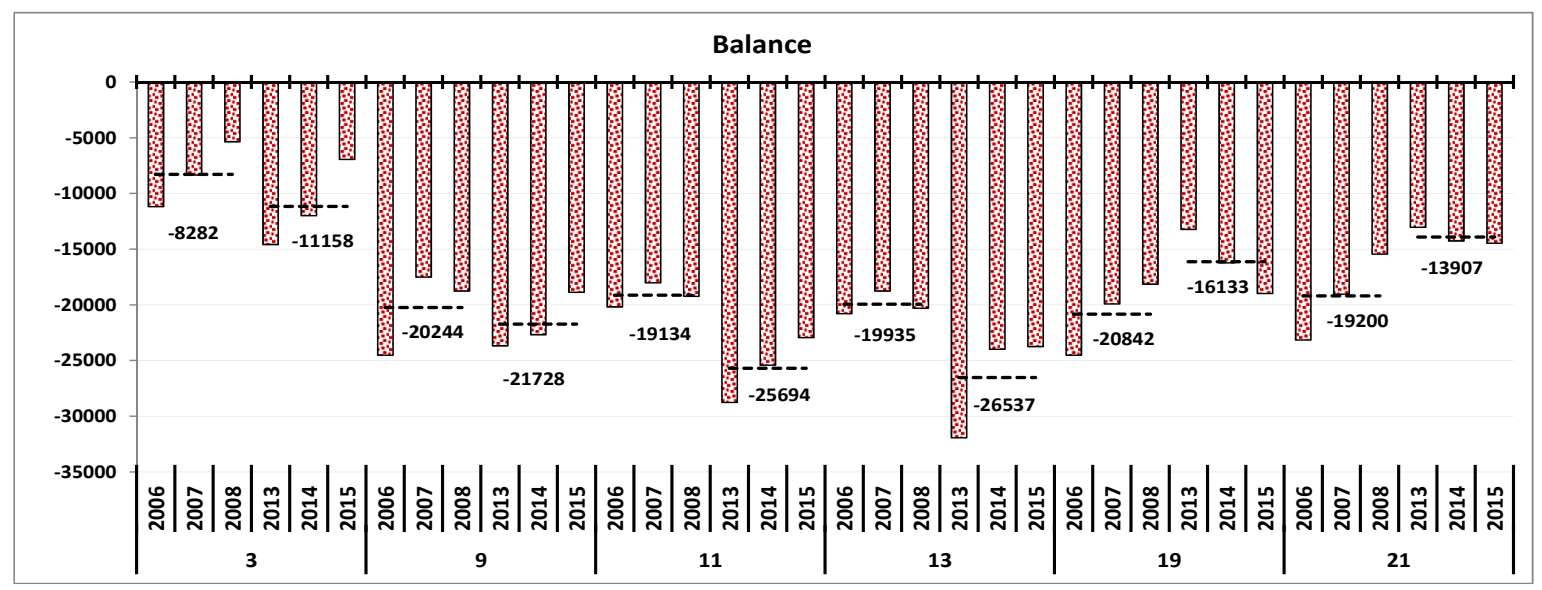

Figure 9: Balance between Profits and Costs (in thousands of $€$ ) in Northern Italy.

Mln $€$ during the period 2013-2015 ${ }^{19}$. Increasing costs are interestingly observed at hour 3 , when both demand and RES generation are at their lowest levels and, simultaneously, both water pumping and thermal units implement a price strategy of high maximum prices (increments across the two samples go from 19 to $67 € / \mathrm{MWh}$ for water pumping, and from 148 to $884 € / \mathrm{MWh}$ for thermal units). This may support the idea that thermal units are recovering in balancing sessions their profits lost on MGP, especially in off-peak hours when the competition from hydro and water pumping is low or even absent in the second sample (see their intra-daily profiles in Figure 2 and bottom panels for awarded offers in

\footnotetext{
${ }^{19}$ Please note that considering the whole Italian market, Terna incurred in costs equal to 1,723 Mln $€$ in 2013 and 1,756 Mln $€$ in 2014, according to AEEGSI (2015).
} 
Figure 4). Indeed, Clò and D'Adamo (2015) already observed that 'the merit-order effect' (daytime switch between solar and gas) has pushed gas producers to concentrate their supply of electricity during off-peak hours' in the MGP market session, when they were looking at the national day-ahead hourly prices, the 'PUN' prices. However, reduced costs are surprisingly observed at hour 19 (when demand is still high and RES-E is low) and at the ramp-down hour 21 (when again both demand and RES are decreasing) because of the competition in quantity from hydro and water pumping units (see again bottom panels for awarded offers in Figure 4, especially for the MB session).

We additionally observe significant cost increases for hydro and thermal power from 2014 to 2015 especially at hours 19 and 21, not well captured in the dynamics of the overall balance. This suggests that market operators may have initially followed old strategies and then some learning mechanisms have taken places supporting the hypothesis that speculations are occurring in the Italian balancing markets.

Overall, our results provide a simple and clear empirical evidence that the strong impact of RES in the generation mix actually induced higher costs for balancing needs for almost all considered hours (excluding hours 19 and 21). We found that thermal and hydro producers are able to exert market power but only at specific hours so that they probably apply a differential strategy related to the strength they have on different market session.

For completeness, we could not conduct a similar investigation for the Italian Southern zone, where the highest share of wind power is located, because only few price observations ${ }^{20}$ are available. Balancing sessions for the South are an extremely thin market and this does not guarantee reliable econometric results (we refer specifically to Section 4.3).

\section{Conclusions}

The paper provides empirical evidence that the increasing RES penetration is affecting the traditional relationship between electricity and fuels prices.

To summarize, we firstly show that renewables are able to substantially reduce the role and influence of fuels in day-ahead sessions, whereas in balancing sessions fossil fuels remain relevant drivers of electricity prices. We find that coal-fired power generation has increased its influence on electricity prices, fostered by coal becoming relatively cheaper than gas. Therefore, the switch from natural gas (the less emission-intensive generation source) to coal raises new challenges for policies aiming at reducing greenhouse gas emissions.

Secondly, we find that the high and sudden RES penetration has reshaped the competitive conditions in electricity market sessions. RES are pushing gas units out of the merit order

\footnotetext{
${ }^{20}$ In Southern MB sessions, "accepted" and "no revoked" type of auctions were available only for hours: 1-3, 8, 13-15, 17-24 during 2013; hours 1, 20-24 during 2014; and hours 9, 13-24 during 2015. Therefore, this information was not sufficient to compute balancing costs for all hours. Furthermore, the inspection of MSD and MB data shows that these market sessions for accepted bids/offers were very thin. For instance, considering just offers, the total accepted quantities awarded on MSD were $196 \mathrm{GW}$ in 2006, $158 \mathrm{GW}$ in 2007 and $216 \mathrm{GW}$ in 2008; whereas we find $23 \mathrm{GW}$ in 2013 and 2014, and just $8 \mathrm{GW}$ in 2015. Moving to the MB sessions, we observed $792 \mathrm{GW}$ in 2006, $810 \mathrm{GW}$ in 2007, 1,017 GW in 2008 in sharp contrast of scale for 186 MW in 2013, $895 \mathrm{MW}$ in 2014 and $830 \mathrm{MW}$ in 2015.
} 
in the day-ahead market ${ }^{21}$ and therefore they revert to real time sessions where they still enjoy a leading role. The closing of a number of gas units relevant for balancing purposes has increased market concentration in this segment when the larger amount of intermittent generation would require even more flexible thermal power generation.

Thirdly, being aware that there are other important price drivers at both day-ahead and balancing levels, we focus on the fuels-electricity nexus to emphasize the possible strategic opportunities to move across market sessions.

Fourthly, confirming that conventional fuels still represent the main source of balancing costs (quantified across years, hours, technologies, market purpose and sessions), we observe their increasing trend from the first to the second sample and from 2014 to 2015, a fact that suggests operators' learning mechanisms and perhaps some coordinated bidding strategies.

Finally, the high share of volatile RES production increases the need of carefully planning and monitoring of the balancing activity. The recent introduction of the fifth intra-day market session in the Italian power exchange has helped in promoting system stability after the increase of intermittent RES production. Our analysis confirms that in the short term a prompt adoption of a capacity market, which is still waiting for an implementation, is the best policy option to help balancing activities and reduce associated costs.

\section{References}

AEEGSI (2015, December). Rapporto annuale dell'autorit per l'energia elettrica ed il gas e il sistema iderico in materia di monitoraggio dei mercati elettrici a pronti, a termine e dei servizi di dispacciamento. 630/2015/EEL.

Bigerna, S., C. A. Bollino, and P. Polinori (2016). Renewable energy and market power in the Italian electricity market. The Energy Journal 37(SI2), 123-144.

Bosco, B., L. Parisio, M. Pelagatti, and F. Baldi (2010). Long-run relations in European electricity prices. Journal of Applied Econometrics 25(5), 805-832.

Bottazzi, G., S. Sapio, and A. Secchi (2005). Some statistical investigations on the nature and dynamics of electricity prices. (1), 54-61.

Brijs, T., K. D. Vos, C. D. Jonghe, and R. Belmans (2015). Statistical analysis of negative prices in European balancing markets. Renewable Energy 80, 53 - 60 .

Chaves-Avila, J. and C. Fernandes (2015). The Spanish intraday market design: A successful solution to balance renewable generation? Renewable Energy 74, 422-432.

Clò, S. and G. D'Adamo (2015). The dark side of the sun: How solar power production affects the market value of solar and gas sources. Energy Economics 49(0), 523 - 530 .

Cruz, A., A. Muoz, J. L. Zamora, and R. Espnola (2011). The effect of wind generation and weekday on Spanish electricity spot price forecasting. Electric Power Systems Research $81(10), 1924-1935$.

\footnotetext{
${ }^{21}$ This is frequently known as the "curse of CCGT units" since flexible newly constructed plants, as well as all gas fired units, are working less hours with respect to their break-even point.
} 
Erdös, P. (2012). Have oil and gas prices got separated? Energy Policy 49, 707 - 718. Special Section: Fuel Poverty Comes of Age: Commemorating 21 Years of Research and Policy.

Fernandes, C., P. Fras, and J. Reneses (2016). Participation of intermittent renewable generators in balancing mechanisms: A closer look into the Spanish market design. Renewable Energy 89, $305-316$.

Gelabert, L., X. Labandeira, and P. Linares (2011). An ex-post analysis of the effect of renewables and cogeneration on Spanish electricity prices. Energy Economics 33, Supplement 1(0), S59 - S65. Supplemental Issue: Fourth Atlantic Workshop in Energy and Environmental Economics.

Gianfreda, A. and L. Grossi (2012). Forecasting Italian electricity zonal prices with exogenous variables. Energy Economics 34(6), 2228-2239.

Gianfreda, A., L. Parisio, and M. Pelagatti (2016a). The impact of RES in the Italian day-ahead and balancing markets. The Energy Journal 37(SI2).

Gianfreda, A., L. Parisio, and M. Pelagatti (2016b). Revisiting long-run relations in power markets with high RES penetration. Energy Policy 94, 432 - 445.

Harvey, A. and S. J. Koopman (1993). Forecasting hourly electricity demand using timevarying splines. Journal of the American Statistical Association 88(424), 1228-1236.

Henriot, A. (2014). Market design with centralized wind power management: Handling low-predictability in intraday markets. Energy Journal 35(1), 99 - 117.

Hirth, L. and I. Ziegenhagen (2015). Balancing power and variable renewables: Three links. Renewable and Sustainable Energy Reviews 50, 1035 - 1051.

Ketterer, J. C. (2014). The impact of wind power generation on the electricity price in Germany. Energy Economics 44(0), 270 - 280.

Mauritzen, J. (2013). Dead battery? Wind power, the spot market, and hydropower interaction in the Nordic electricity market. Energy Journal 34(1), $103-123$.

Mulder, M. and B. Scholtens $(2013,9)$. The impact of renewable energy on electricity prices in the Netherlands. Renewable Energy 5\%, 94-100.

Müsgens, F., A. Ockenfels, and M. Peek (2014). Economics and design of balancing power markets in Germany. International Journal of Electrical Power \& Energy Systems 55, 392 $-401$.

Newbery, D., G. Strbac, and I. Viehoff (2016). The benefits of integrating European electricity markets. Energy Policy 94, 253 - 263.

Pelagatti, M. M. (2015). Time Series Modelling with Unobserved Components. Chapman and Hall/CRC. 
Sapio, A. (2015). The effects of renewables in space and time: A regime switching model of the Italian power price. Energy Policy 85, 487 - 499.

Woo, C., I. Horowitz, J. Moore, and A. Pacheco (2011). The impact of wind generation on the electricity spot-market price level and variance: The Texas experience. Energy Policy 39(7), 3939 - 3944. Special Section: Renewable energy policy and development. 


\section{Appendices}

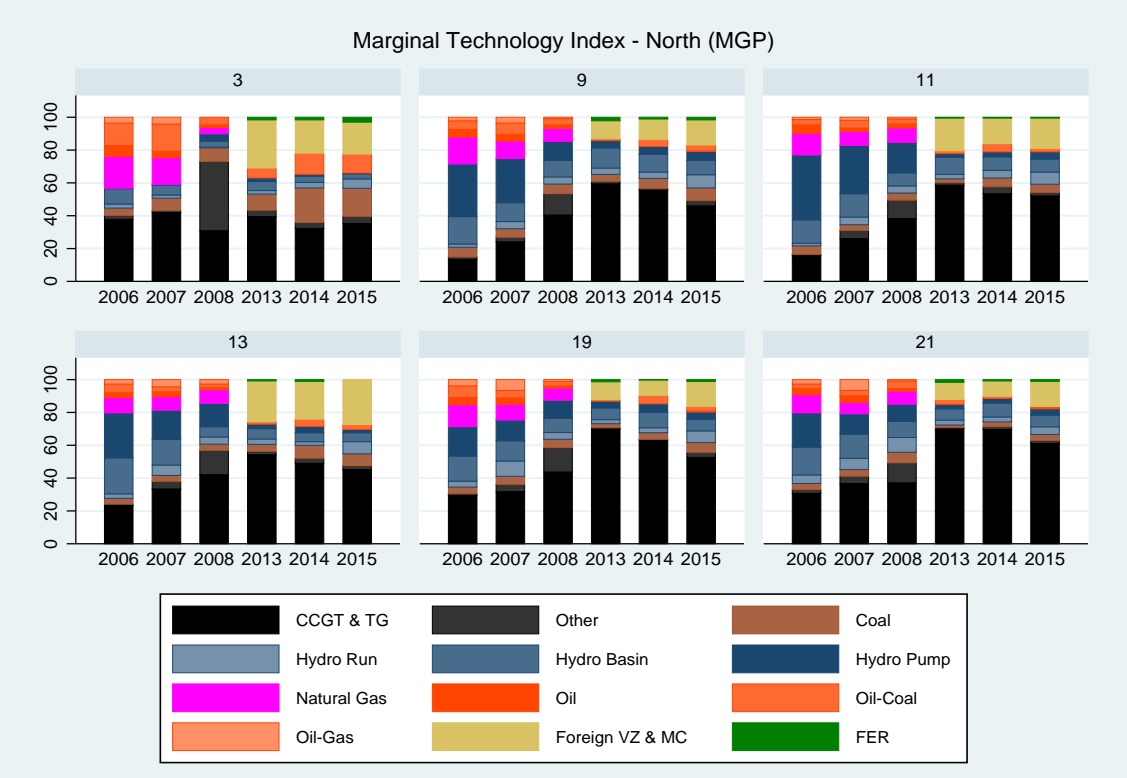

Figure 10: Percentages of the Marginal Technology Index representing the technologies determining the system marginal price on the day-ahead market (MGP) in Northern Italy. VZ and MC mean "virtual zones" and "market coupling" respectively. In addition, FER stands for wind, solar, geothermal and other renewable sources.

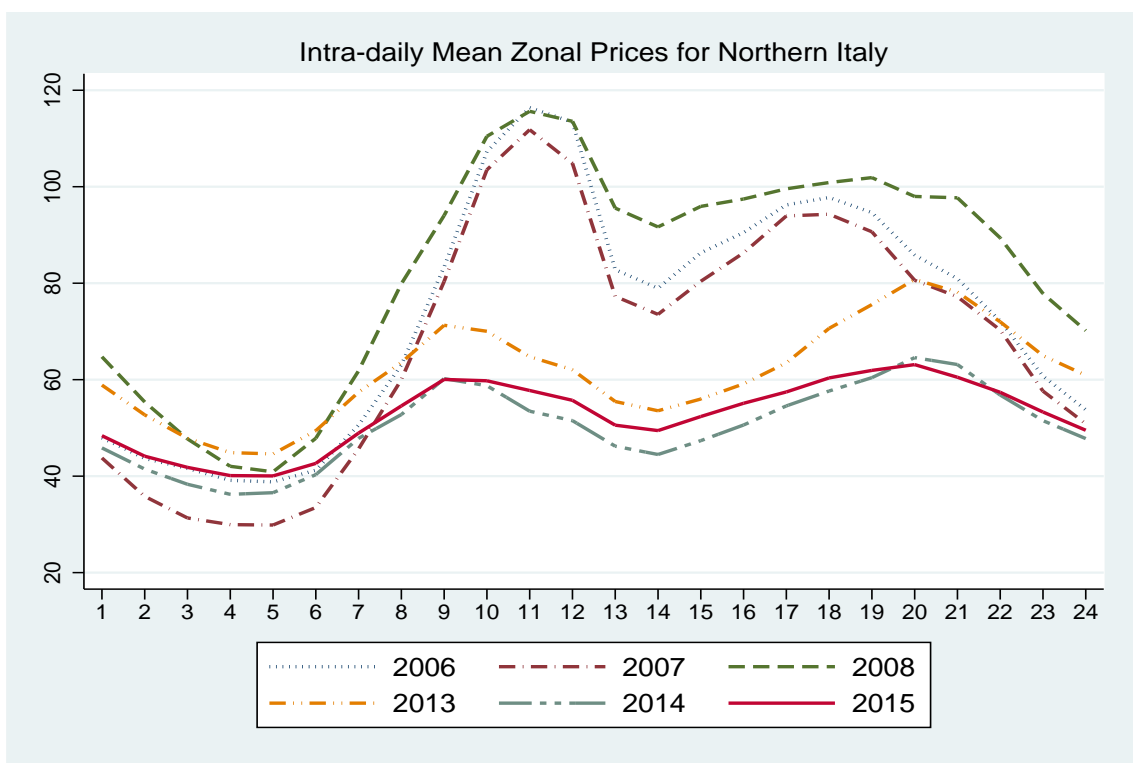

Figure 11: Intra-daily profiles of Zonal Prices in Northern Italy for considered years. 


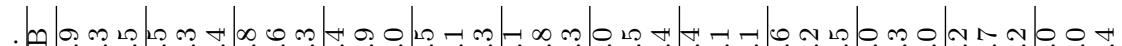

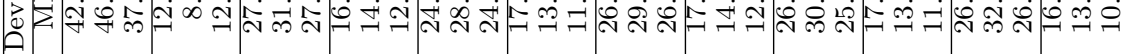

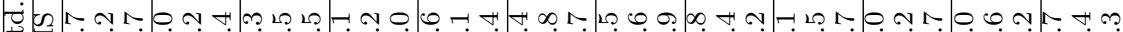

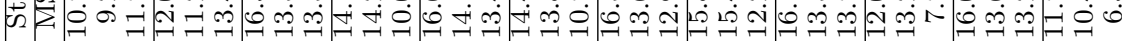

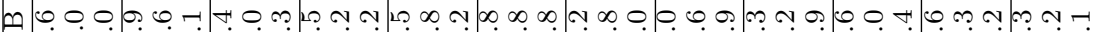
= दर

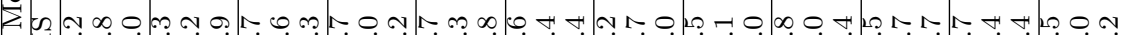
莺

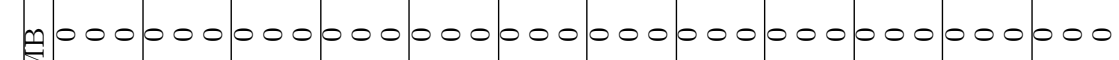
帛 ×

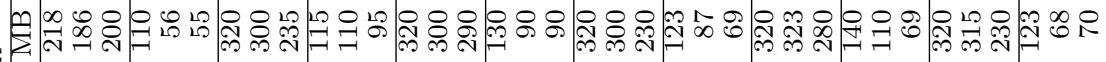
$\bar{z}$

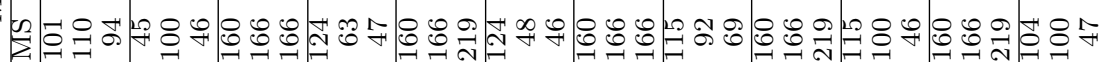

m ऐ)

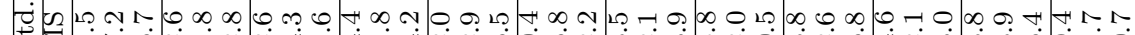
隹

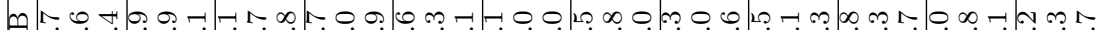
00 즁

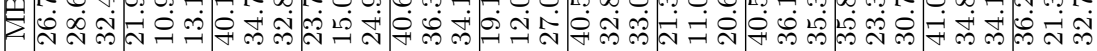

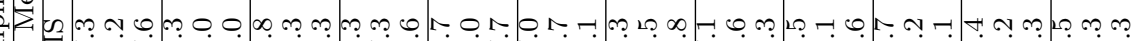
כ Z Z

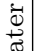
$\exists$

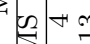

000000000000000000000000000000000000

0000000

0,00000

$\infty 00$

o0, 000 年

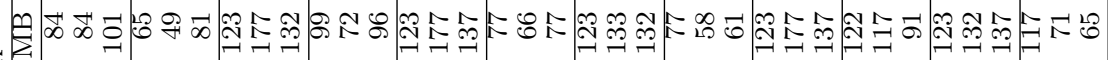

承

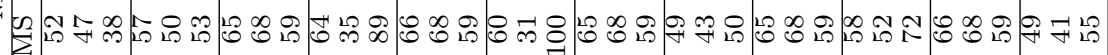

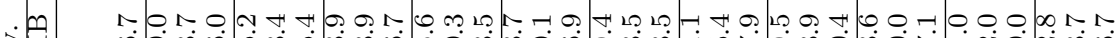

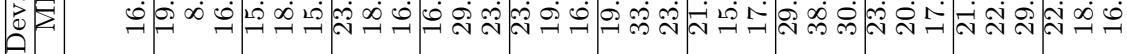

D 放

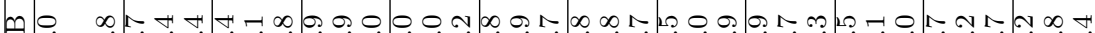

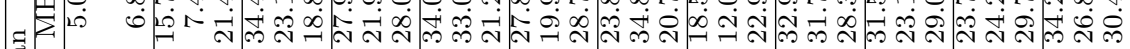

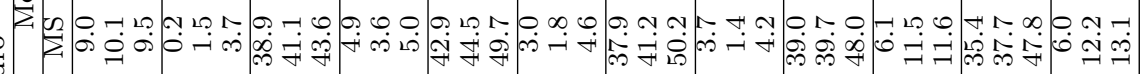
:

m la 000000000000000000000000000000000 苗

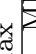

2000000000000000000000000000000000000

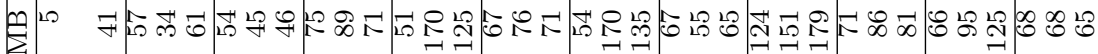

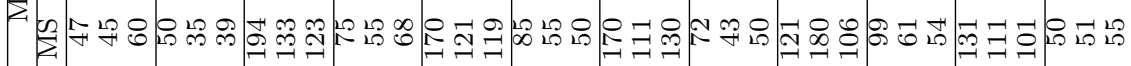
F

$m=0 \quad m$ m

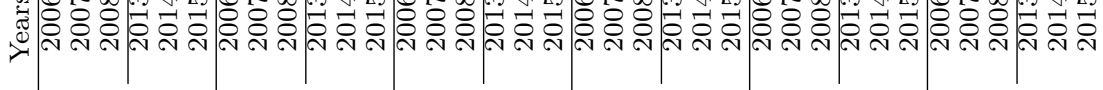
콕

$\because$

9

$\vec{N}$ 


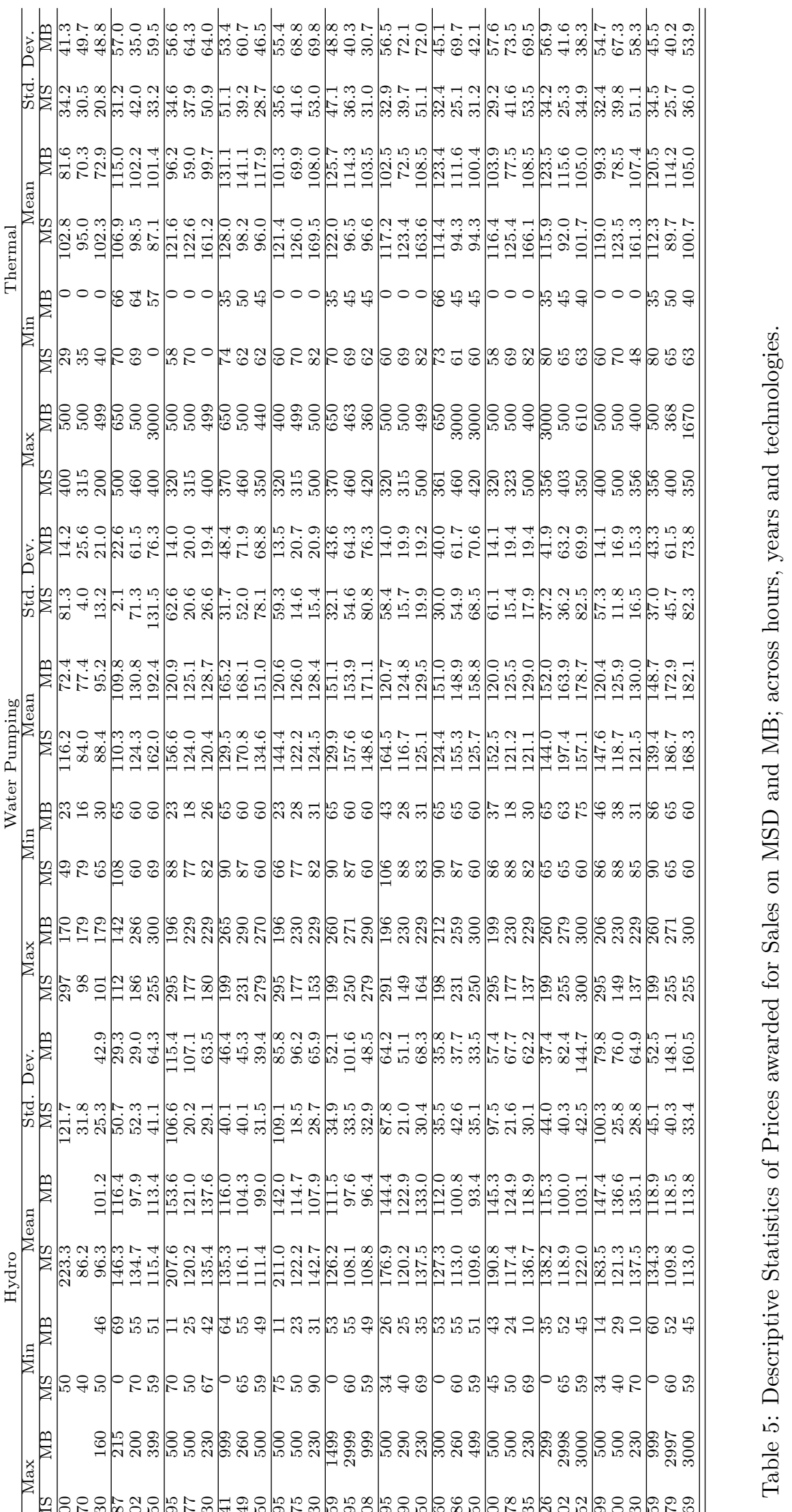
7 -

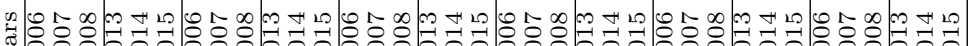

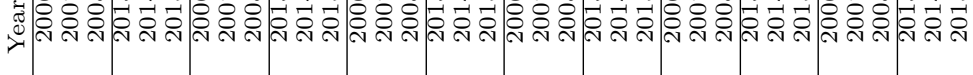

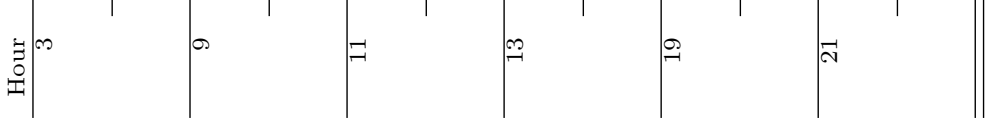

